\title{
The effect of branching (star architecture) on poly(D,Llactide) (PDLLA) degradation and drug delivery
}

DOI:

10.1021/acs.biomac.6b01524

\section{Document Version}

Accepted author manuscript

Link to publication record in Manchester Research Explorer

\section{Citation for published version (APA):}

Burke, J., Donno, R., d'Arcy, R., Cartmell, S., \& Tirelli, N. (2016). The effect of branching (star architecture) on poly(D,Llactide) (PDLLA) degradation and drug delivery. Biomacromolecules.

https://doi.org/10.1021/acs.biomac.6b01524

\section{Published in:}

Biomacromolecules

\section{Citing this paper}

Please note that where the full-text provided on Manchester Research Explorer is the Author Accepted Manuscript or Proof version this may differ from the final Published version. If citing, it is advised that you check and use the publisher's definitive version.

\section{General rights}

Copyright and moral rights for the publications made accessible in the Research Explorer are retained by the authors and/or other copyright owners and it is a condition of accessing publications that users recognise and abide by the legal requirements associated with these rights.

\section{Takedown policy}

If you believe that this document breaches copyright please refer to the University of Manchester's Takedown Procedures [http://man.ac.uk/04Y6Bo] or contact uml.scholarlycommunications@manchester.ac.uk providing relevant details, so we can investigate your claim.

\section{OPEN ACCESS}


Subscriber access provided by The University of Manchester Library

Article

\section{The effect of branching (star architecture) on poly(D,L- lactide) (PDLLA) degradation and drug delivery}

Jason Burke, Roberto Donno, Richard d'Arcy, Sarah Cartmell, and Nicola Tirelli

Biomacromolecules, Just Accepted Manuscript • DOI: 10.1021/acs.biomac.6b01524 • Publication Date (Web): 08 Dec 2016

Downloaded from http://pubs.acs.org on January 11, 2017

\section{Just Accepted}

"Just Accepted" manuscripts have been peer-reviewed and accepted for publication. They are posted online prior to technical editing, formatting for publication and author proofing. The American Chemical Society provides "Just Accepted" as a free service to the research community to expedite the dissemination of scientific material as soon as possible after acceptance. "Just Accepted" manuscripts appear in full in PDF format accompanied by an HTML abstract. "Just Accepted" manuscripts have been fully peer reviewed, but should not be considered the official version of record. They are accessible to all readers and citable by the Digital Object Identifier (DOI®). "Just Accepted" is an optional service offered to authors. Therefore, the "Just Accepted" Web site may not include all articles that will be published in the journal. After a manuscript is technically edited and formatted, it will be removed from the "Just Accepted" Web site and published as an ASAP article. Note that technical editing may introduce minor changes to the manuscript text and/or graphics which could affect content, and all legal disclaimers and ethical guidelines that apply to the journal pertain. ACS cannot be held responsible for errors or consequences arising from the use of information contained in these "Just Accepted" manuscripts. 


\title{
The effect of branching (star architecture) on
}

\section{poly(D,L-lactide) (PDLLA) degradation and drug}

\section{delivery}

\author{
Jason Burke ${ }^{1}$, Roberto Donno ${ }^{1}$, Richard d'Arcy ${ }^{1}$, Sarah Cartmell $^{2 *}$, Nicola Tirelli $^{1 *}$ \\ ${ }^{1}$ NorthWest Centre of Advanced Drug Delivery (NoWCADD), Manchester Pharmacy School, \\ University of Manchester, Oxford Road, Manchester, M13 9PT, United Kingdom \\ ${ }^{2}$ School of Materials, University of Manchester, Grosvenor Street, Manchester, M13 9PL, United \\ Kingdom
}

Keywords: polylactides, branching, degradability, nanoparticles, drug delivery, osteoblasts 


\begin{abstract}
This study focuses on the comparative evaluation of star (branched) and linear poly(L,D-lactic acid) (PDLLA) as degradable materials employed in controlled release.

The polymers were prepared via ring-opening polymerization initiated by decanol (linear), pentaerythritol (4-armed star) and dipentaerythritol (6-armed star), and processed both in the form of films and nanoparticles. Independently on the length or number of their arms, star polymers degrade slower than linear polymers, possibly through a surface (vs. bulk) mechanism Further, the release of a model drug (atorvastatin) followed a zero-order-like kinetics for the branched polymers, and a first order kinetics for linear PDLLA. Using NHOst osteoblastic cells, both linear and star polymers were devoid of any significant toxicity and released atorvastatin in a bioavailable form; cell adhesion was considerably lower on star polymer films, and the slower release from their nanoparticles appeared to be beneficial to avoid atorvastatin overdosing.
\end{abstract}




\section{Introduction}

This study focuses on the influence of polymer topology on functional properties, and more precisely on whether a single-point branching (star architecture) can affect the performance of a non-crystallizable and degradable polyester structure (poly(D,L lactic acid), PDLLA) as a matrix for drug delivery.

Branching can provide a number of advantages, which in the context of polyesters have been recently reviewed by us ${ }^{1}$. In short, they include: a) a higher degree of functionality, which is advantageous for the conjugation/complexation of therapeutically active compounds and the appropriate presentation of groups capable of biological targeting or evasion (e.g. from the mononuclear phagocytic system (MPS)); b) enhanced stability of micellar self-assembly, in principle allowing for the preparation of unimolecular micelles ${ }^{2,3}$; c) reduced viscosity at high concentration.

Although significant efforts have been paid in the synthesis and physico-chemical characterization of branched and above all star aliphatic polyesters (as reviewed by Cameron in $2011^{4}$ ), yet to date comparatively little attention has been paid to whether the mechanism of hydrolytic degradation is affected by the presence of branching points, and whether this may have an influence on a functional property, e.g. the release of an active principle loaded in the polymer.

The use of polyols (commonly glycerol and erythritol derivatives, but also poly(vinyl alcohol) (PVA)) as initiators in lactone ring-opening polymerization is a common method for the synthesis branched/star polymers and has been widely employed ${ }^{5-10}$; nevertheless, the effects of branching on the degradability and drug release of the resulting materials have been considerably less studied, with the group of Kissel being one of the few to extensively investigate the matter in the early ' 90 s and early 2000s. For example, they showed that branched PLGA produced using glucose or PVA as initiators had a faster in vivo degradation than linear analogues ${ }^{11}$, and that star block copolymers of poly(ethylene glycol) (PEG) and poly(glycolic acid-co-lactic acid) (PLGA), and PVA-PLGA brushes degraded faster than their linear counterparts ${ }^{12}$. Further, it appears that increasing the length 
and thus the hydrophobicity of PLGA branches may switch the degradation from a surface to a bulk mechanism ${ }^{13}$. To our knowledge, the glucose-initiated star PLGA is the only member of this family that has reached the stage of commercial exploitation, e.g. in the Sandostatin LAR $®$ Depot, a form of microspheres loaded with octreotide (a somatostatin analogue), which has received approval for use in the USA by the FDA in 1998 for the treatment of acromegaly and tumor-associated diarrhoea $^{14}$.

However, it is often difficult to generalize these findings and point out clear advantages (or disadvantages) of branched structures; for example, the above studies report on constructs that are typically more hydrophilic than most polyesters.

Here we have prepared poly(D,L lactic acid) (PDLLA) star polymers, comparing their degradation and drug release behaviour with that of linear PDLLA derivatives of comparable molecular weight. The star PDLLAs were synthesised from two polyol initiators, i.e. pentaerythritol (tetrafunctional: 4-armed polymers), dipentaerythritol (hexafunctional: 6-armed polymers), employing 1-decanol for the synthesis of linear polymers used here as a control (Scheme 1). All polymers were processed in the form of homogeneous and transparent films via solution casting.

For the drug release behaviour we have selected atorvastatin as a model drug; hydrophobic statins such as atorvastatin and simvastatin are increasingly finding application outside the field of cholesterol control, e.g. because of anti-inflammatory activity ${ }^{15,16}$, most intriguingly to stimulate bone formation ${ }^{17}$ and therefore also as anti-osteoporotic drugs ${ }^{18,}{ }^{19}$, as also demonstrated by previous publications of one of the authors ${ }^{20}$. Although most studies have focused on simvastatin, in this study we have preferred to employ atorvastatin as a model drug, due to its higher (about 2fold $^{21}$ ) activity: simvastatin is per se inactive and requires the hydrolysis of its lactone ring. 
Scheme 1. Branched vs. linear PDLLA structures were produced via ring-opening polymerization of racemic lactide in toluene, using decanol, pentaerythritol and dipentaerythritol as initiators (top left). The polymers were then processed in the form of films via solvent casting on circular glass supports for further use in 24-well plates, e.g. as substrates for cells. After a stage of selection, some polymers were finally produced in the form of nanoparticles through an oil-inwater emulsion method and the use of a PEGylated emulsifier (Pluronic L64).

\section{Experimental Section}

\subsection{Materials}

Synthesis. 1-dodecanol, phosphate buffered solution (PBS), N,N-dimethylformamide (DMF), Nmethylpirrolidinone (NMP) (Sigma Aldrich), hexane, dichloromethane (DCM), tetrahydrofurane (THF) (Fisher) were used as supplied. Toluene (Fisher) was refluxed under argon over metallic 
sodium and benzophenone (Fiscer) until the dark purple colour of the reduced diphenylketyl radical was stable, and then distilled at $110^{\circ} \mathrm{C}$. Racemic 3,6-dimethyl-1,4-dioxane-2,5-dione (Sigma Aldrich) was recrystallized twice in dry toluene, dried under vacuum and then stored in a desiccation chamber (phosphorous pentoxide, Fisher) until needed. Pentaerythritol and dipentaerythritol (Sigma Aldrich) were purified by sublimation under reduced pressure (ca. 10 mbar) at $210^{\circ} \mathrm{C}$ and $220^{\circ} \mathrm{C}$, respectively, and maintained under dry air (desiccator) until needed; tin(II) 2-ethylhexanoate (Sigma Aldrich) was purified by microdistillation at $140^{\circ} \mathrm{C}$ at room pressure and stored under argon.

Cell culture. NHOst (Clonetics ${ }^{\mathrm{TM}}$ ) human osteoblast cells were purchased from Lonza. Fetal bovine serum (FBS), glutamine, antibiotics (Penicillin/Streptomycin), ascorbic acid, $\beta$ glycerophosphate disodium salt hydrate (BGP), Dulbecco's modified eagle medium (DMEM) and atorvastatin calcium salt trihydrate were all purchased from Sigma Aldrich. The Alkaline Phosphatase Activity Assay was purchased from Abcam. The Alamar Blue assay solution was purchased from Life Technologies while the Bicinchoninic Acid (BCA) kit was purchased from Sigma Aldrich. Alexa Fluor 488 Phalloidin and Hoechst fluorescent stains were purchased from ThermoFisher for use in microscopy experiments. All other chemicals were purchased from Fisher Scientific.

\subsection{Physico-chemical characterisation}

FT-IR: Spectra were recorded in ATR mode on polymer films obtained by evaporating THF solutions using a heated Golden Gate $\left(120^{\circ} \mathrm{C}\right)$ coupled to a Tensor 27 spectrometer (Bruker).

${ }^{1}$ H-NMR: spectra were recorded on $10 \mathrm{mg} / \mathrm{mL}$ polymer solutions in deuterated chloroform $\left(\mathrm{CDCl}_{3}\right)$ using a $300 \mathrm{MHz}$ NMR spectrometer (Bruker). Results were analysed using Mestrenova (Mestrelab) software.

Gel Permeation Chromatography: Gel permeation chromatography was performed on a PLGPC50 PLUS (Polymer Laboratories) featuring two 0.5 x 30cm mixed C columns, operated in THF 
containing $250 \mathrm{ppm} \mathrm{BHT}$, at $30^{\circ} \mathrm{C}$ and with a flow rate of $1 \mathrm{~mL} / \mathrm{min}$. A universal calibration was carried out using a series of approximately monodisperse linear polystyrene standards. Triple detection (refractive index, viscometer and dual angle light scattering detector at $15^{\circ}$ and $90^{\circ}$ ) was used to obtain absolute molecular weight distributions and Mark-Houwink parameters.

Thermal Analysis. Thermogravimetric analysis (TGA) and differential scanning calorimetry (DSC) were performed on samples produced from polymer films under nitrogen atmosphere at a rate of $5^{\circ} \mathrm{C} / \mathrm{min}$, respectively, on a TGA Q500 and on a Q2000 DSC instrument (both TA Instruments). DSC was also used to estimate any crystalline drug possibly present in the polymer matrix.

\subsection{PDLLA synthesis}

All polymerization experiments were carried out in a parallel fashion (typically 6 experiments) under mechanical agitation using a Tornado Plus ${ }^{\circledR}$ reactor (Radleys). $150 \mathrm{~mL}$ vessels were loaded under dry argon with $30 \mathrm{~g}$ of 3,6-dimethyl-1,4-dioxane-2,5-dione (0.42 mol) and appropriate amounts of initiators; these corresponded to 16.8 or $8.4 \mathrm{mmol}$ of $\mathrm{OH}$ groups for the multifunctional pentaerythritol (4 OH groups), dipentaerythritol (6 OH groups), tripentaerythritol (8 OH groups) and to 4.2 and $2.8 \mathrm{mmol}$ for the monofunctional 1-dodecanol). $25 \mathrm{~mL}$ of toluene were added always under dry argon, and the vessels were then heated $\left(110^{\circ} \mathrm{C}\right.$ in the heating block) under stirring until complete dissolution of the polymer. $5 \mathrm{~mL}$ of a toluene solution of tin(II) 2-ethylhexanoate at appropriate concentration (twofold molar excess relative to $\mathrm{OH}$ groups) were finally added and the reaction mixture was left stirring at the same temperature for $24 \mathrm{hr}$. After cooling to room temperature, the mixture was diluted with $30 \mathrm{~mL}$ of DCM and the resulting solution was precipitated in cold hexane using $50 \mathrm{~mL}$ centrifuge tubes; in each of them $10 \mathrm{~mL}$ of polymer solution were slowly dropped into $20 \mathrm{~mL}$ of hexane under stirring. After centrifugation, the process was repeated twice and finally the samples were placed in a vacuum oven $35^{\circ} \mathrm{C}$, slowly decreasing the pressure to 0.1 mbar and keeping the material under vacuum over a period of 24 Hrs. The 
powdered samples were kept in a desiccation chamber $\left(\mathrm{P}_{2} \mathrm{O}_{5}\right)$ for 24 hrs, aliquoted, sealed and stored at $4^{\circ} \mathrm{C}$ until needed.

${ }^{1} \mathbf{H}$ NMR $\left(\mathrm{CDCl}_{3}\right)$ : linear polymers $\delta=0.55-0.65\left(a\right.$, terminal $\left.\mathrm{CH}_{3}\right), 1.15-1.20\left(b, \mathrm{CH}_{2}\right.$ from dodecane moieties $), 1.55-1.65\left(f\right.$, terminal $\left.\mathrm{C}(\mathrm{H}) \mathrm{CH}_{3}\right)$, 1.55-1.75 $\left(d\right.$, main chain $\mathrm{CH}\left(\mathrm{CH}_{3}\right), 2.55-2.75$ ( $h, \mathrm{COH}$ (terminal)), 4.15-4.25 (c, $\mathrm{CCH}_{2} \mathrm{O}$ methylene), 4.30-4.50 ( $g, \mathrm{CH}\left(\mathrm{CH}_{3}\right)$ terminal), 5.10-5.30 $\operatorname{ppm}\left(e, \mathrm{CH}\left(\mathrm{CH}_{3}\right)\right.$ main chain $)$.

4-armed $\delta=1.55-1.65\left(f\right.$, terminal $\left.\mathrm{C}(\mathrm{H}) \mathrm{CH}_{3}\right)$, 1.55-1.75 $\left(d\right.$, main chain $\mathrm{CH}\left(\mathrm{CH}_{3}\right), 2.55-2.75(h$, $\mathrm{COH}$ (terminal)), 3.70-3.80 (c', unreacted $\mathrm{CCH}_{2} \mathrm{O}$ methylene) 4.15-4.25 (c, $\mathrm{CCH}_{2} \mathrm{O}$ methylene), 4.30-4.50 ( $\mathrm{g}, \mathrm{CH}\left(\mathrm{CH}_{3}\right)$ terminal), 5.10-5.30 ppm (e, $\mathrm{CH}\left(\mathrm{CH}_{3}\right)$ main chain).

6-armed $\delta=1.55-1.65\left(f\right.$, terminal $\left.\mathrm{C}(\mathrm{H}) \mathrm{CH}_{3}\right), 1.55-1.75\left(d\right.$, main chain $\mathrm{CH}\left(\mathrm{CH}_{3}\right), 2.55-2.75(h$, $\mathrm{COH}$ (terminal)), 3.35-3.45 ( $j, \mathrm{OCH}_{2} \mathrm{C}$ dipentaerythritol moiety), 3.70-3.80 ( $c$ ', unreacted $\mathrm{CCH}_{2} \mathrm{O}$ methylene) 4.15-4.25 (c, $\mathrm{CCH}_{2} \mathrm{O}$ methylene), 4.30-4.50 ( $g, \mathrm{CH}\left(\mathrm{CH}_{3}\right)$ terminal), 5.10-5.30 ppm (e, main chain $\left.\mathrm{CH}\left(\mathrm{CH}_{3}\right)\right)$.

FT-IR (film on ATR crystal): for all polymers $2993\left(v_{\mathrm{as}} \mathrm{CH}_{3}\right), 2943\left(\mathrm{v}_{\mathrm{as}} \mathrm{CH}_{3}\right), 2879(v \mathrm{CH})$, $1723(v \mathrm{C}=\mathrm{O}), 1450\left(\delta_{\mathrm{s}} \mathrm{CH}_{3}\right), 1385,1265,1185\left(v_{\text {as }} \mathrm{C}-\mathrm{C}(=\mathrm{O})-\mathrm{O}\right), 1124$ (shoulder, most likely $v_{\mathrm{s}} \mathrm{C}-$ $\mathrm{C}(=\mathrm{O})-\mathrm{O}$ ), 1083 (most likely $\vee \mathrm{C}-\mathrm{C}-\mathrm{O}) \mathrm{cm}^{-1}$. For comparison, the monomer bands are located at $3000\left(v_{\text {as }} \mathrm{CH}_{3}\right), 2950\left(v_{\mathrm{as}} \mathrm{CH}_{3}\right), 2895(v \mathrm{CH}), 1753(v \mathrm{C}=\mathrm{O}), 1445\left(\delta_{\mathrm{s}} \mathrm{CH}_{3}\right), 1385(), 1235\left(v_{\text {as }} \mathrm{C}-\right.$ $\mathrm{C}(=\mathrm{O})-\mathrm{O}), 1145\left(v_{\mathrm{s}} \mathrm{C}-\mathrm{C}(=\mathrm{O})-\mathrm{O}\right), 1092(v \mathrm{C}-\mathrm{C}-\mathrm{O}), 1050,924,650 \mathrm{~cm}^{-1}$.

\subsection{Film preparation and characterization}

$150 \mathrm{mg}$ of $20 \% \mathrm{w} / \mathrm{v}$ polymer solutions in 90:10 THF/DMF (85:15, 95:5 ratios and NMP in lieu of DMF were also tried, but provided inhomogeneous films) were deposited on $\varnothing=13 \mathrm{~mm}$ circular glass coverslips, and the solvent was gradually removed through a stepwise reduction in pressure (from room pressure to 1 mbar in 24 hours) in a vacuum oven at $35^{\circ} \mathrm{C}$, and then in a Genevac ${ }^{\mathrm{TM}}$ centrifugal evaporator $\left(10 \mathrm{mbar}, 35^{\circ} \mathrm{C}\right)$. Atorvastatin-loaded samples were prepared similarly with the dissolution of drug in the solvent mixture prior to addition to polymer samples. For the release 
studies, films were prepared to give a loading of $0.1 \% \mathrm{wt}$. (drug/polymer). The film roughness and thicknesses were assessed using a Dektak- $8^{\circledR}$ (Veeco) profilometer.

Degradation \& Drug Release. The films on the circular glass supports were placed in 24-well polystyrene plates and incubated in $2 \mathrm{~mL}$ distilled water at $37^{\circ} \mathrm{C}$; please note that at complete release one would have max $15 \mu \mathrm{g} / \mathrm{mL}$, well below the reported atorvastatin solubility in water (around $1 \mathrm{mg} / \mathrm{mL}$, http://www.drugbank.ca/drugs/DB01076) and therefore under sink conditions). The samples were then removed, dried at room temperature/pressure, weighed and dissolved in THF to assess polymer degradation via GPC.

$0.1 \%$ wt. atorvastatin-loaded films were used for the release studies. At regular intervals, in each well the supernatant was completely removed and replaced with $2 \mathrm{~mL}$ of fresh water; the supernatant was filtered through $0.2 \mu \mathrm{m}$ PTFE filters and analyzed using an isocratic water/acetonitrile (50:50) mobile phase in a Agilent 1100 HPLC instrument (ChemStation software) equipped with a C18 reverse phase column (Sigma Aldrich) and a UV/Vis detector at $245 \mathrm{~nm}$ (Schambeck SFD S3210 UV/Vis).

Atomic Force Microscopy (AFM). All measurements were performed at $25^{\circ} \mathrm{C}$ with a Molecular Force Probe 3D AFM (MFP-3D Asylum Research, Oxford Instruments, Abingdon, UK). A silicon cantilever, OTESPA (Bruker, Camarillo, CA), with a nominal spring constant $=42.0 \mathrm{~N} \mathrm{~m}^{-1}$ was used both for imaging and for adhesion force measurements. Imaging: all images were acquired in tapping mode in air at a scan frequency of $1 \mathrm{~Hz}$. For each sample, several areas $(5 \mu \mathrm{m} \times 5 \mu \mathrm{m}$ or 3 $\mu \mathrm{m} \times 3 \mu \mathrm{m})$ were imaged. Images were analysed with Igor-pro/Asylum Research AFM software (Version 13) in order to calculate the root mean square (RMS) roughness. Mean and standard deviation values are obtained from at least 3 images. Measurement of adhesion forces: measurements on mica were used to calibrate the deflection sensitivity of the cantilever. The spring constant of the cantilever was calculated with the thermal method and value obtained was $=$ to 42.8 $\mathrm{N} \mathrm{m}^{-1}$. For each sample, several areas were investigated $(5 \mu \mathrm{m} \times 5 \mu \mathrm{m}$ or $3 \mu \mathrm{m} \times 3 \mu \mathrm{m})$ and adhesion force maps were acquired with a spatial resolution of $0.062 \mu \mathrm{m}^{2}$ for the $5 \mu \mathrm{m}^{2}$ images and 
of $0.022 \mu \mathrm{m}^{2}$ for the $3 \mu \mathrm{m}^{2}$ images ( $20 \times 20$ force curves acquired per area). All force curves were acquired with a loading/unloading rate $=1 \mu \mathrm{m} \mathrm{s}^{-1}$ and the maximum force applied ranged between $50 \mathrm{nN}$ and $70 \mathrm{nN}$. The adhesion forces between the AFM tip and the surface of the samples were determined from the unloading (retraction) force curves. The difference between the minimum force and the force felt at a large distance from the surface is the adhesion force. Mean and standard deviation values are obtained from at least 4 different force maps.

\subsection{Nanoparticle preparation and characterization}

In a typical experiment, oil-in-water $(\mathrm{O} / \mathrm{W})$ emulsions were prepared my mixing $4 \mathrm{~mL}$ of a $10 \%$ wt. PDLLA solutions in dichloromethane (possibly containing atorvastatin at a target $0.01 \% \mathrm{wt}$. relative to PDLLA) with $16 \mathrm{~mL}$ (4X excess) of 2\% wt. Pluronic L64 (poly(ethylene glycol)-blpoly(propylene glycol)-bl-poly(ethylene glycol), $\overline{M_{n}}=2,900 \mathrm{~g} / \mathrm{mol}$ ) aqueous solution under high frequency sonication $(23 \mathrm{KHz})$ in an ice bath. A Soniprep 150 (MSE) probe sonicator fitted with an exponential $3 \mathrm{~mm}$ probe tip and working at $15 \mu \mathrm{A}$ (transformation ratio of 7:1) was used for this purpose; the probe tip was placed approximately $2 \mathrm{~cm}$ beneath the surface of mixture. The oil phase (polymer/drug solutions) was added dropwise to the aqueous phase via a burette and the mixture was sonication for additional 10 mins after the end of the addition. The suspensions were stirred overnight at room temperature $(250 \mathrm{rpm})$ to evaporate dichloromethane, and large aggregates were removed via gentle centrifugation at $125 \mathrm{~g}(\mathrm{RCF})$ for $5 \mathrm{mins}$; the nanoparticles were then pelleted via centrifugation at $2580 \mathrm{~g}(\mathrm{RCF})$ for 15 mins, washing the pellet with distilled water and repeating the centrifugation twice before filtering the suspension through $0.45 \mu \mathrm{m}$ filters, centrifuged, aspirated, air dried, weighed and resuspended at known concentrations in sterile water. The amount of loaded drug was measured by sampling $1 \mathrm{~mL}$ of suspensions, pelleting it in Eppendorf tubes (6048g (RCF) for 10mins), drying the pellet, dissolving it in dichloromethane and finally measuring the atorvastatin absorbance at $245 \mathrm{~nm}$, using non-loaded polymer nanoparticles as blanks and atorvastatin samples as references. 
The nanoparticle size was measured using a Zetasizer Nano ZS instrument (Model ZEN2500, Malvern Instruments Ltd.; Malvern, UK) at a scattering angle of $173^{\circ}$ and at a temperature of $25^{\circ} \mathrm{C}$. In stability studies, measurements were carried out over a 10 day period in $\mathrm{PBS}$ at $37^{\circ} \mathrm{C}$.

Drug Release. A $2 \mathrm{~mL}$ aliquot of a freshly prepared $5 \mathrm{mg} / \mathrm{mL}$ nanoparticle suspension $(1 \% \mathrm{wt}$. atorvastatin in the nanoparticles) in distilled water was incubated at $37^{\circ} \mathrm{C}$. At different time points, the nanoparticles were pelleted via centrifugation as described above, removing the supernatant and replacing it with a fresh $2 \mathrm{~mL}$ of aliquot of water. The concentration of the drug in the supernatant was then assessed by measuring the absorbance of the solutions at $245 \mathrm{~nm}$ via UV/Vis spectroscopy using a PerkinElmer Lambda 35 UV/Vis spectrophotometer. Release is presented as a percentage of the average drug content determined previously for any given batch of nanoparticles.

\subsection{Cell Culture}

General procedures. NHOst cells were cultured in DMEM supplemented with $10 \%$ FBS, $1 \%$ antibiotics, $2 \mathrm{mM}$ glutamine, $50 \mu \mathrm{g} / \mathrm{mL}$ ascorbic acid and $10 \mathrm{mM}$ BGP. All cells were cultured at $37^{\circ} \mathrm{C}$ and under $5 \% \mathrm{CO}_{2}$ and used to maximum passage number of 7.

For experiments performed on supported polymer films, the latter were placed in the wells of 24well plates, and sterilized by exposing them to decreasing concentrations of ethanol $(70,50$ and 20\%; 5 min incubation for each concentration). They were then thoroughly rinsed 3 times with PBS prior to the addition of the cells in their culture medium (density $=50,000$ cells/well).

For experiments involving polymer nanoparticles, cells were cultured overnight at $60 \%$ confluency prior to the addition of treatment. In a typical experiment, $125 \mu \mathrm{L}$ of $1.6,8$ or $16 \mathrm{mg} / \mathrm{mL}$ nanoparticle dispersions were added to $125 \mu \mathrm{L}$ of pre-filtered serum-free medium and the resulting suspension was added to $1.75 \mathrm{~mL}$ serum-containing cultures to obtain final nanoparticle concentrations respectively of $0.1,0.5$ or $1 \mathrm{mg} / \mathrm{mL}$. The medium was replaced every 3 days with medium containing freshly prepared nanoparticles at the same concentration. 
RT-PCR analysis. PureLink ${ }^{\circledR}$ RNA mini kits (Applied Biosystems ${ }^{\mathrm{TM}}$ ) were used for RNA isolation while High Capacity cDNA Reverse Transcription Kits (Applied Biosystems ${ }^{\mathrm{TM}}$ ) were used for cDNA synthesis. TaqMan ${ }^{\circledR}$ Gene Expression Master Mix was used alongside bone morphogenetic protein-2 (BMP2), runt-related transcription factor - 2 (RUNX2), alpha - 1 - type 1 - collagen (COLA1), 18S and Glyceraldehyde-3-Phosphate Dehydrogenase (GAPDH) and TaqMan ${ }^{\circledR}$ gene expression assays (Life Technologies) were used for polymerase chain reaction experiments.

Briefly, cells were lysed and RNA was extracted and purified using an RNA extraction kit. Following, RNA was used in reverse transcription to provide cDNA for thermal cycling with TaqMan gene expression assay systems. All reactions were carried out in MicroAmp® Fast Optical 96-Well Reaction Plates (Applied Biosciences) and carried out on a StepOnePlus ${ }^{\mathrm{TM}}$ (Life Technologies) RT-PCR analyser. All reactions were carried out for a total of 40 thermal cycles. Results were run against house-keeping genes (18s or GAPDH) in a $\Delta \Delta \mathrm{CT}$ quantitative evaluation method and all results are expressed as fold change in gene expression relative to negative control samples.

Metabolic activity. Cells were allowed to adhere to surfaces, cultured for 3 days (on polymer films or exposed to nanoparticle-containing media), analysed directly using an Alamar Blue reagent following the manufacturers recommendations, and normalised against protein content, which were measured via BCA assay as described above. All results are presented relative to untreated cell samples grown on TCPS.

BCA assay. Following $8 \mathrm{hrs}$ incubation after cell seeding, the substrates were washed in PBS to remove unattached cells and any debris, and trypsinised to remove attached cells; the supernatant was centrifuged in $2 \mathrm{~mL}$ centrifuge tubes, and the resulting pellets were resuspended in fresh PBS and placed in a 96-well plate alongside the working BCA solutions. Sample dilutions were carried out where needed. Results were normalised by expressing them as a \% of the protein content measured when cells were cultured on TCPS. 
Alkaline Phosphatase Assay: An alkaline phosphatase activity assay kit was used to determine the osteoblastogenic activity of NHOst cells in response to the drug-loaded nanoparticles at various concentrations. Measurements were taken after 3 or 7 days of treatment and enzyme incubation was carried out for $1 \mathrm{hr}$ at $25^{\circ} \mathrm{C}$. Results are calculated in terms of enzymatic reaction activity as a function of time.

Fluorescence microscopy. Cells/Films were washed in PBS and a fixing solution of 4\% paraformaldehyde was added to each well for 10 mins. Wells were washed thoroughly before being stained with Alexa Fluor 488 Phalloidin (actin) and Hoechst (nucleus) staining solution for 20 mins, following manufacturers recommendations. Films were washed in PBS, carefully removed and placed on glass slides for analysis. Films were coated in PBS throughout the acquisitions to protect cells. Fluorescence microscopy acquisition was carried out on a Leica DMI6000 B inverted microscope equipped with a Leica DFC7000 T 2.8MP colour camera and controlled via MicroManager software. All images were processed using ImageJ.

\section{Results and discussion}

\subsection{Synthesis of linear and star PDLLA and film preparation}

Polymer synthesis. The ROP of polyesters is commonly carried out in the monomer melt at temperatures between 140 and $180^{\circ} \mathrm{C}$, although the use of solvents allows to lower the polymerization temperature to reduce the probability of back-biting and degradation reactions. Pentaerythritol has been successfully employed as a multifunctional initiator for the bulk polymerization of lactides ${ }^{22-24}$, but in pilot experiments we noticed that polyols with higher functionality such as dipentaerythritol and tripentaerythritol (respectively 6 and $8 \mathrm{OH} / \mathrm{molecule}$ ) were completely insoluble in the monomer. We therefore chose polymerization in a hydrophobic and easy to dry solvent such as toluene, where both pentaerythritol and dipentaerythritol are soluble; tripentaerythritol is only partially soluble and its use as an initiator in refluxing toluene yielded PDLLA with large batch-to-batch variations (although with consistent conversion: 78- 
$82 \%$ ), thus it was not further employed in this study. Please note that the use of 1-decanol in the preparation of linear polymers was due to the volatility of most monofunctional alcohols, which may result in their poorly reproducible concentration at the polymerization temperature $\left(>100^{\circ} \mathrm{C}\right)$.

Monomer consumption during the polymerization was monitored through FT-IR spectroscopy and showed completion typically $<12$ hrs; the final polymers showed the PDLLA characteristic fingerprint region and the complete absence of the lactide ring breathing vibration at $936 \mathrm{~cm}^{-1}$ (Figure 1B) ${ }^{25}$, ensuring the absence of unreacted monomer in the materials. Six polymers were prepared: two each for linear, 4-armed star and 6-armed star architecture (Table 1).

Table 1. Physico-chemical characterization data for linear and branched PDLLA.

\begin{tabular}{|c|c|c|c|c|c|c|c|c|c|c|c|}
\hline \multirow[t]{2}{*}{ Sample $^{\mathrm{a}}$} & \multicolumn{2}{|c|}{$\begin{array}{l}\text { No of arms } \\
\text { (NMR) }\end{array}$} & \multicolumn{2}{|c|}{$\begin{array}{l}\text { DP per arm } \\
\text { (NMR) }\end{array}$} & \multicolumn{5}{|c|}{$\mathrm{GPC}^{\mathrm{b}}$} & \multirow{2}{*}{$\begin{array}{c}\text { TGA } \\
\begin{array}{l}\text { Onset } \\
\left({ }^{\circ} \mathrm{C}\right)^{\mathrm{h}}\end{array}\end{array}$} & \multirow{2}{*}{ 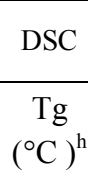 } \\
\hline & Theor & Meas $^{\mathrm{c}}$ & Theor $^{d}$ & Meas $^{\mathrm{e}}$ & $\begin{array}{l}\text { Theor. } \overline{M_{n}} \\
(\mathrm{~g} / \mathrm{mol})^{\mathrm{f}}\end{array}$ & $\begin{array}{c}\overline{M_{n}} \\
(\mathrm{~g} / \mathrm{mol})\end{array}$ & $Đ$ & $\begin{array}{c}{[\eta]} \\
(\mathrm{dL} / \mathrm{g})^{\mathrm{g}}\end{array}$ & $a^{\mathrm{g}}$ & & \\
\hline Lin_100 & 1 & $=$ & 100 & 94.8 & 14,400 & 15,100 & 1.17 & 0.444 & 1.06 & 205 & 42.3 \\
\hline Lin_150 & 1 & $=$ & 150 & 145.0 & 21,600 & 22,350 & 1.27 & 0.587 & 0.94 & 208 & 44.6 \\
\hline 4_25 & 4 & 3.60 & 25 & 26.9 & 14,400 & 15,100 & 1.06 & 0.179 & 0.87 & 181 & 39.9 \\
\hline 4_50 & 4 & 3.52 & 50 & 55.3 & 28,800 & 29,800 & 1.11 & 0.256 & 0.86 & 192 & 41.4 \\
\hline 6_25 & 6 & 5.26 & 25 & 27.9 & 21,600 & 23,200 & 1.11 & 0.115 & 0.85 & 185 & 30.1 \\
\hline $6 \_50$ & 6 & 5.02 & 50 & 59.1 & 43,200 & 47,900 & 1.14 & 0.258 & 0.85 & 194 & 34.8 \\
\hline
\end{tabular}

\footnotetext{
${ }^{\mathrm{a}}$ Typical conversions: $95 \%$ wt. for linear polymers, $88-90 \% \mathrm{wt}$. for 4 -armed stars, $84-88 \%$ wt. for 6 -armed stars.

${ }^{\mathrm{b}}$ Size distributions can be found in the Supporting Information (Figure 1S)

${ }^{\mathrm{c}}$ Calculated by comparing peak integrals for reacted ( $c$ in Figure $1 \mathrm{~A} ; \delta \square \square \square 4.15-4.25 \mathrm{ppm}$ ) and unreacted $\mathrm{OH}$ groups $(c$ '; $\delta \square \square \square 3.8-3.85 \mathrm{ppm})$.

${ }^{\mathrm{d}}$ DP (degree of polymerization) per arm calculated as the molar ratio between monomer and alcohol groups in the feed.

${ }^{\mathrm{e}}$ Calculated by comparing peak integrals for reacted methylene (4.15-4.25 ppm, $c$ in Figure 1A) and main chain methyl groups (1.55$1.75 \mathrm{ppm}, d$ in Figure 1A) and normalising against the actual no. of arms, as calculated ${ }^{\mathrm{a}}$.

${ }^{\mathrm{f}}$ Calculated as the arm DP * number of arms * molecular weight of the repeating unit.

${ }^{\mathrm{g}}$ The intrinsic viscosity and the parameter $a$ from the Mark-Houwink equation were obtained via triple detection GPC.

${ }^{\mathrm{h}}$ Analyses conducted at $5^{\circ} \mathrm{C} / \mathrm{min}$. The $\mathrm{Tg}$ values are identical in the presence or absence of $1 \% \mathrm{wt}$. atorvastatin.
}

The two linear polymers had, respectively, similar molecular weight to the 4-armed and the 6armed stars with degree of polymerization $(D P)=25$. The end group analysis indicated that $>80 \%$ of the $\mathrm{OH}$ groups of the two polyols initiated PDLLA chains, corresponding to an effective degree of branching of around 3.5 for the "4-armed" star polymers and 5 for the "6-armed". For homogeneity, we have nevertheless kept the original nomenclature. The slightly lower degree of 
branching of the star polymers determined a marginally higher than expected degree of polymerization for each of their arms (compare fourth and fifth column in Table 1). GPC showed that all polymers have monomodal molecular weight distribution (see Supporting Information, Figure S1) with rather narrow dispersity, which would indicate the substantial absence of linear chains initiated by water traces in the reaction environment; the use of triple detection also allowed to estimate the intrinsic viscosity and the Mark-Houwink parameter a, which are both sensitive to the compactness of the polymer coil; as expected (and as previously shown for pentaerythritolinitiated PLLA ${ }^{26}$ ), the values of both parameters for the star polymers were significantly lower than those for the linear analogues.

Film preparation. Films were produced from all polymers via solvent casting, with volatiles being evaporated under reduced pressure at $35^{\circ} \mathrm{C}$ in a centrifugal evaporator (Genevac EZ-2; SP Scientific) to maximize both efficacy in removal and homogeneity in thickness. Initial attempts with low boiling solvents (THF, DCM, acetone), however, still produced inhomogeneous films, while higher boiling ones (NMP, toluene) often suffered of incomplete removal. At the end of a lengthy optimization procedure, the best results were provided by a 9:1 THF/DMF mixture, which yielded films with a thickness in the range of $350-400 \mu \mathrm{m}$ with a relative roughness in the range of $0.5-2 \%$ (referred to the film thickness; see Supporting Information, Table S1). The thermal analysis of the six polymers was performed on such films; it highlighted a progressive decrease in glass transition temperature ( $\mathrm{Tg}$ ) with increasing degree of branching (Figure 1C and Table 1), which is probably a result of the lower likelihood of entanglements between the polymer chains; a similar effect has been reported for pentaerythritol-initiated PLLA ${ }^{27}$. A marginal decrease in thermal stability of the branched polymers vs. their linear counterparts can also be noted (Figure 1D and Table 1), and may be related to an easier back-biting mechanism of depolymerisation in the chain portions near to the branching point. 


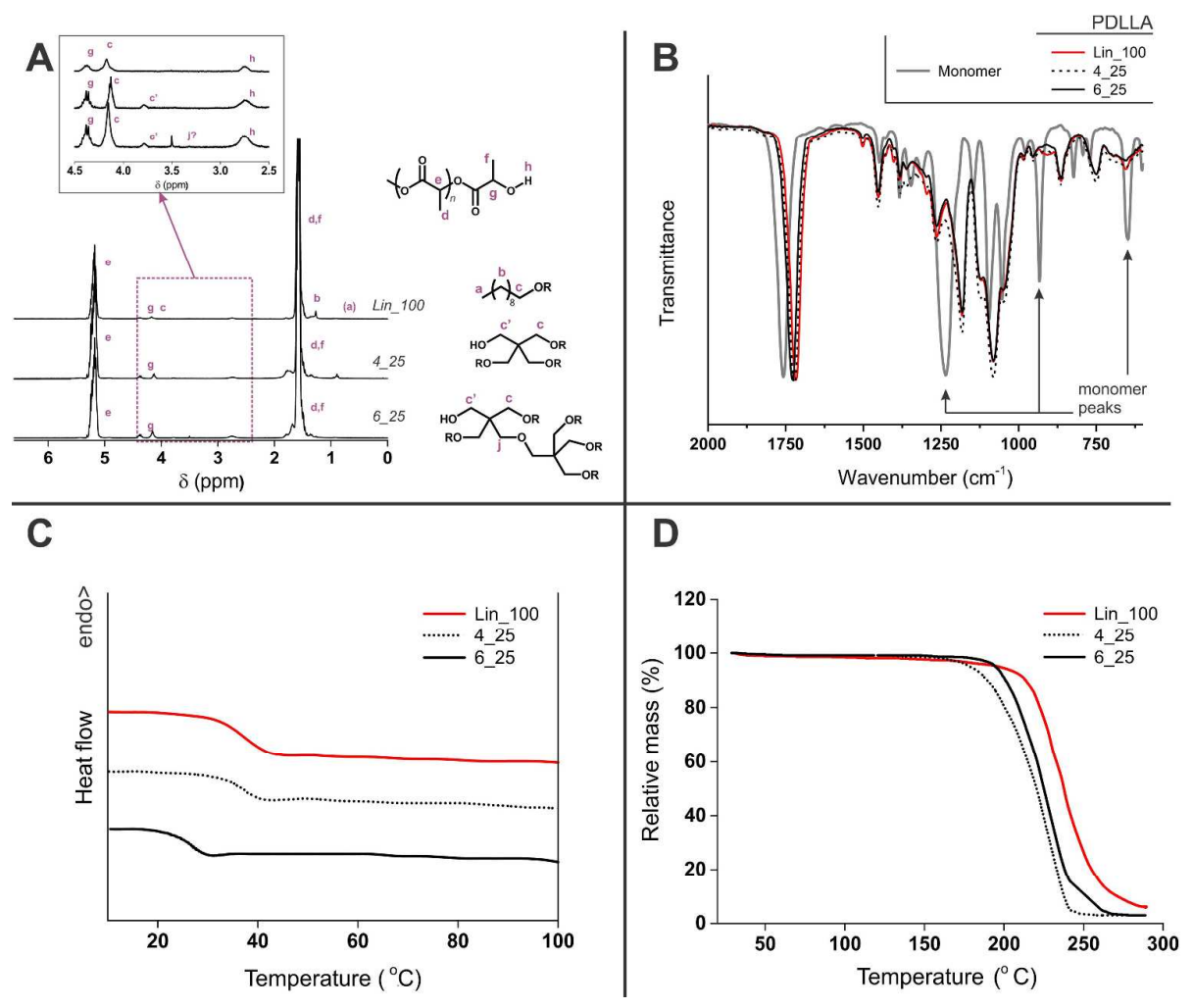

Figure 1. $\boldsymbol{A} .{ }^{1} \mathrm{H}$ NMR spectra of three PDLLA with different degree of branching (Lin_100 and $4 \_25$ have similar molecular weight, 4_25 and 6_25 have the same arm length; see Table 1) and assignments of their peaks to the polyester main chain and initiator groups. The inset presents a magnification of the central area of the spectra where end groups resonances can be seen. $\boldsymbol{B}$. The different degree of branching in the three PDLLA samples introduced no distinctive feature in the IR spectra, whereas all polymers showed major differences from the monomer spectrum. $\boldsymbol{C}$. DSC traces of the three PDLLA samples. All samples contained atorvastatin at a $2.5 \%$ wt. loading, but no melting peak associated to the drug could be detected in the $120-140^{\circ} \mathrm{C}$ region (not shown). D. TGA traces of the three polymers.

The low temperature of the film preparation process allows also for the incorporation of drugs with minimal risks of thermal degradation. In the films, atorvastatin was typically incorporated at a concentration of $0.1 \% \mathrm{wt}$. in the polymer; in order to highlight its possible phase separation from PDLLA, we also prepared films with concentrations up to $2.5 \%$ wt., which in no case showed any melting endotherm around $135^{\circ} \mathrm{C}$ (melting point of the drug), thereby indicating the absence of phase-separated, crystalline drug domains also in the samples with lower drug loadings. 


\subsection{Degradation of PDLLA films}

Here, we refer to erosion as the loss of solid material, and degradation as the associated reduction in molecular weight. To evaluate the effects of branching on the erosion and degradation of PDLLA, thin films were monitored over time in water at $37^{\circ} \mathrm{C}$.

Both the film erosion (Figure 2A) and the degradation (Figure 2B) of the linear polymers were considerably more rapid than those of their branched counterparts, with at least twice larger reductions in the film mass and in $\overline{M_{n}}$ at any time point. We ascribe the slower hydrolysis of the star polymers to a decreased solubility of water close to the branching point; by favoring a non-random hydrolysis mechanism (preferred at the chain termini), this would also explain the lower dispersity index of stars in the degradation. Importantly, this is likely to be less noticeable with longer arms.

At a macroscopic level, the accelerated degradation of the linear macromolecules was accompanied by a loss of integrity of their films already by day 15 (small insets in Figure 2C), whereas the branched polymers always retained their shape. Further, the surface of the linear polymer films rapidly covered with cavities and reliefs ('craters' and 'bubbles'; see large picture on the right of Figure 2C), which were visible also on branched polymers but in much lower numbers.

AFM was employed for a lower-scale analysis of the surface features of these films (Figure 2D), it is worth pointing out that we were only able to perform this analysis at a relatively early stage of the degradation (up to day 7), because at later time points the high relief of the surface features did not allow reliable AFM measurements. In short, at a sub-micron scale linear and star polymers provided virtually indistinguishable film morphology and polarity both in the pristine form and during degradation: the surface roughness (Figure 2D, left) showed an identically large increase after one week of exposure to water, and also the adhesion force between film surfaces and AFM tip increased for both polymers upon degradation (Figure 2D, right). In the last analysis, large error bars would suggest that the pristine/degraded difference is not statistically significant; at a more careful observation, it is noticeable that the surfaces are very heterogeneous, with very polar areas (red in Figure 3) intermixed with regions similar to the pristine polymers (yellow/green in Figure 3). 
A

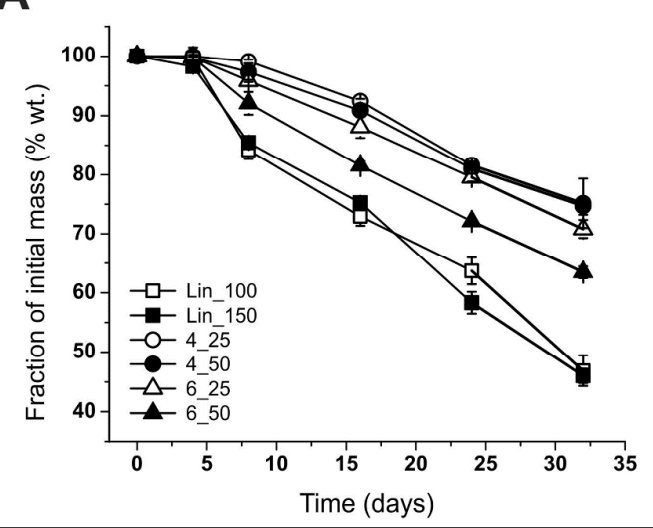

B

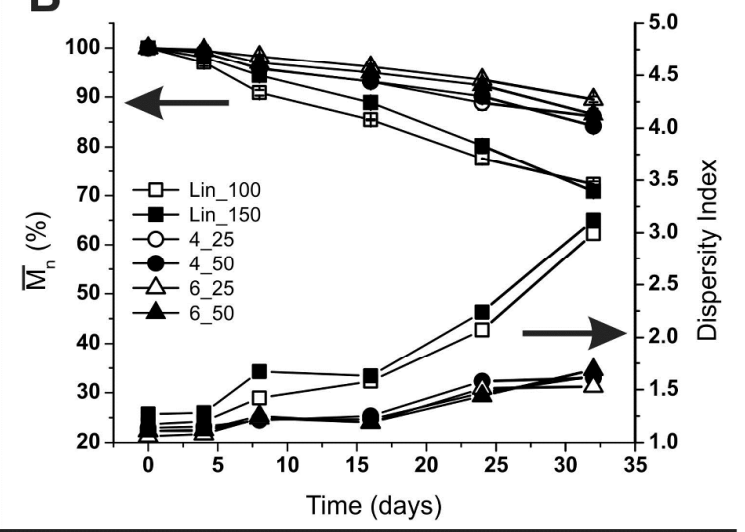

C

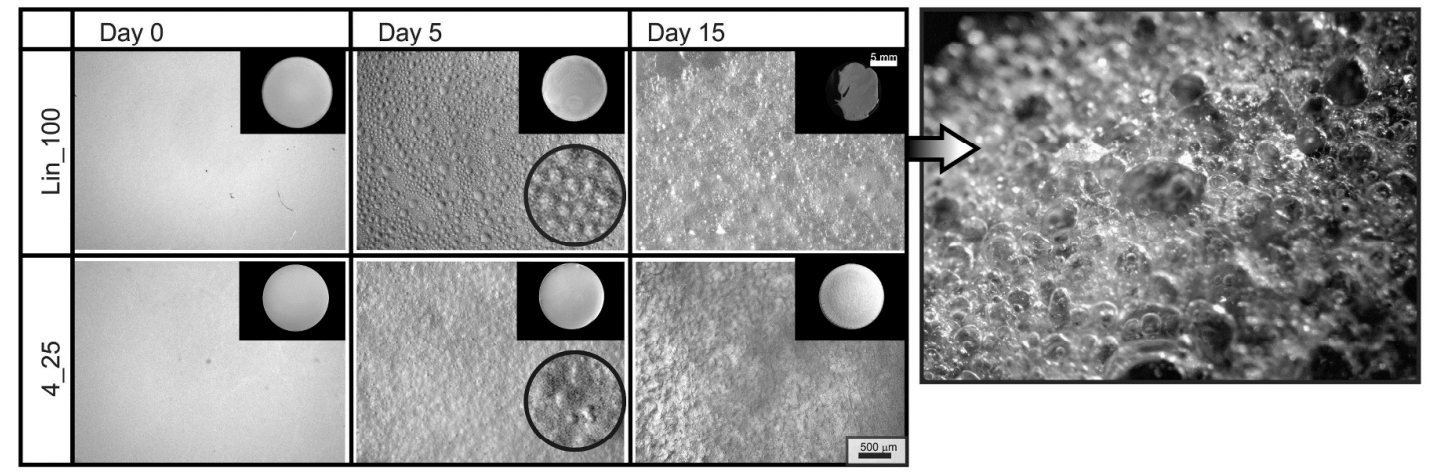

D
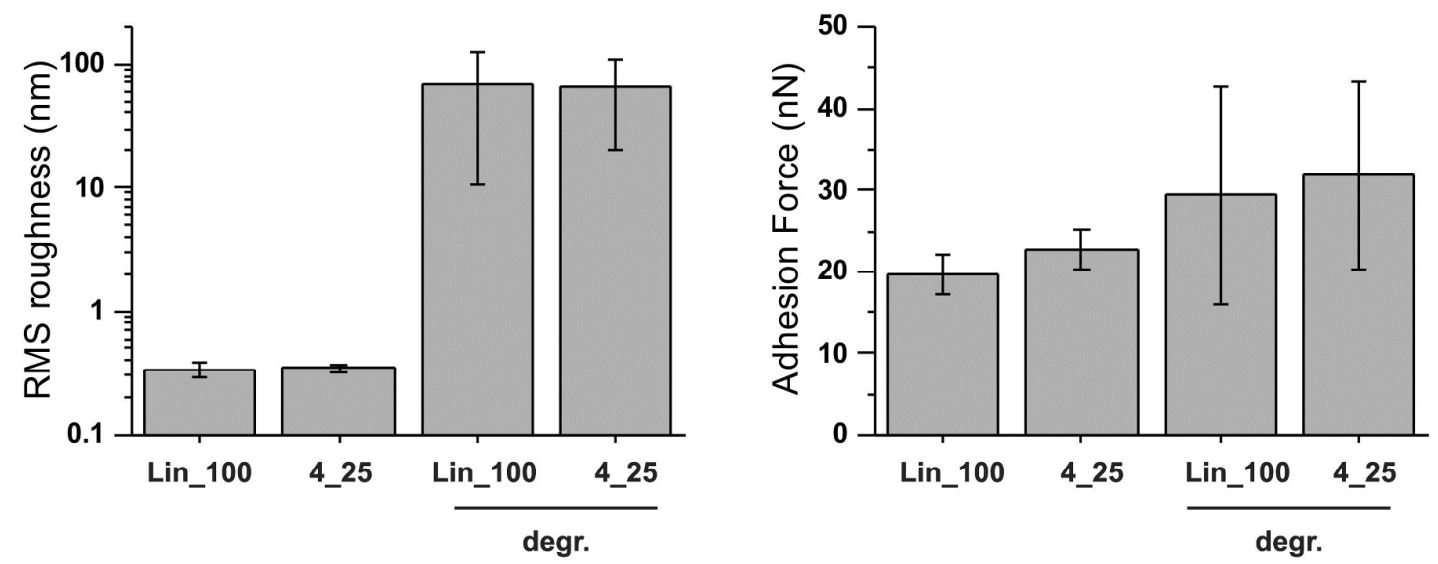

Figure 2. A. Erosion profile of PDLLA films during hydrolysis at $37^{\circ} \mathrm{C}$. B. Degradation profiles of PDLLA films at $37^{\circ} \mathrm{C}$. The left axis reports weight average molecular weight data, the right one those of dispersity index (both from triple detection GPC measurements in THF) and the two arrows link the data points to the respective axes. $\boldsymbol{C}$. Low magnification images of Lin_100 and $4 \_25$ film surfaces during the erosion process. At day 7 both PDLLA developed at day 15 the Lin_100 film had lost its overall integrity (small inset) and completely changed its morphology (picture on the right hand side). On the contrary, the 4-armed star polymer still maintained its shape and developed clear but all-inall more modest signs of surface degradation; the 6-armed polymers showed an identical behaviour (not shown). $\boldsymbol{D}$. Roughness (left) and adhesion force to the cantilever (right) as obtained from AFM measurements; the analysis was performed only on two polymers (Lin_100 and 4_25, with virtually identical molecular weight), as representative respectively of the linear and the branched polymers, since the actual molecular weight of the polymers or the functionality of the branching point seemed to have a negligible role in the degradation behaviour. The degraded samples were exposed to water for seven days. 
Lin_100 4_25

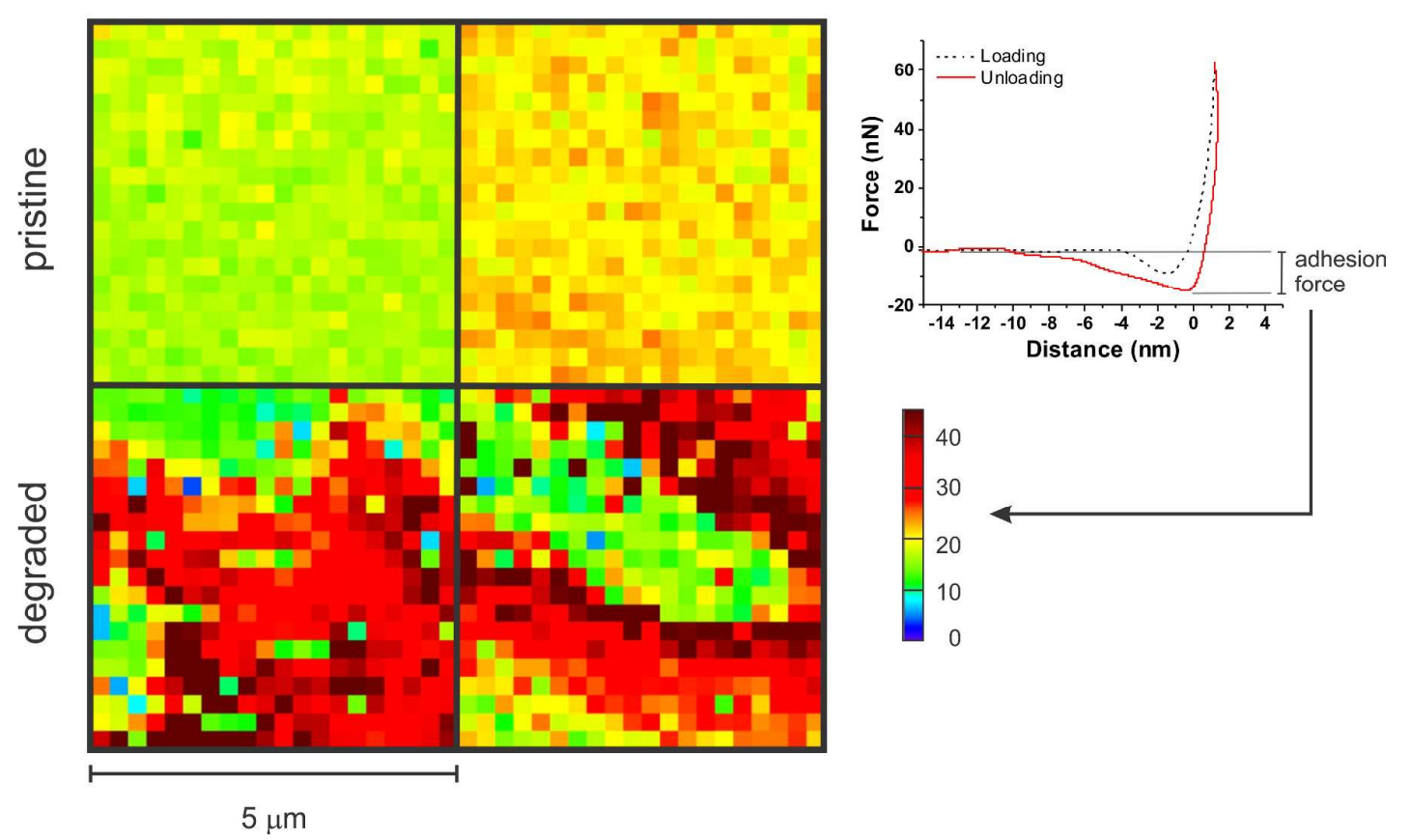

Figure 3. Adhesion maps for Lin_100 and 4_25 PDLLA films following 7 days incubation at $37^{\circ} \mathrm{C}$. The values of adhesion forces were obtained from the differences between loading and unloading nanoindentation curves (a typical example shown in the right part of the figure). The relative elastic modulus maps are presented in Supporting Information, Figure S2.

The adhesion recorded on the polar areas present only in the degraded samples is more than double that observed in less polar areas or in non-degraded samples, which therefore confirms the heterogeneous (and likely autocatalytic) character of degradation. Further, the polar areas appeared to be softer (lower relative elastic modulus, see Supporting Information, Figures S2 and S3) than the less polar ones and the pristine samples; this is likely a consequence of the presence of traces water plasticizing the material, therefore further confirming that degradation has occurred in these regions.

Only one statistically relevant difference between linear and star polymers was recorded, i.e. the presence of domains with a typical size $<100 \mathrm{~nm}$, which appeared only on the surface of the linear polymer films during degradation (Figure 4). We are inclined to consider them as composed of the dodecyl chains present as terminal groups only in the linear polymers: these groups, do not undergo hydrolytic degradation, are likely to phase separate from PDLLA, are mechanically different from it and considerably less polar. Nanoindentation would appear to suggest the degraded linear polymers 
to exhibit lower modulus values (distribution peaked $<3 \mathrm{GPa}$ vs. around $5 \mathrm{GPa}$, see Supporting Information, bottom graphs in Figure S2), but the difference is not statistically significant.

For a mechanistic interpretation, it is useful recapitulating that A) despite their accelerated degradation, mass loss and loss of integrity, at a sub-micron level the surface of the linear polymer films seemed relatively similar to that of the star ones, suggesting the presence of similar species; B) even when the films of star polymers had lost a significant fraction of their initial mass (e.g. about $30 \%$ at day 32 ), yet the macromolecules exhibited very moderate changes in both the average molecular weight and in its dispersity (Đ always $<1.7$ ); nanoindentation can probe materials up the first hundreds of nanometers and may suggest (see Supporting Information, Figure S2) degraded linear polymers to be softer than the branched, whereas the pristine materials are indistinguishable.

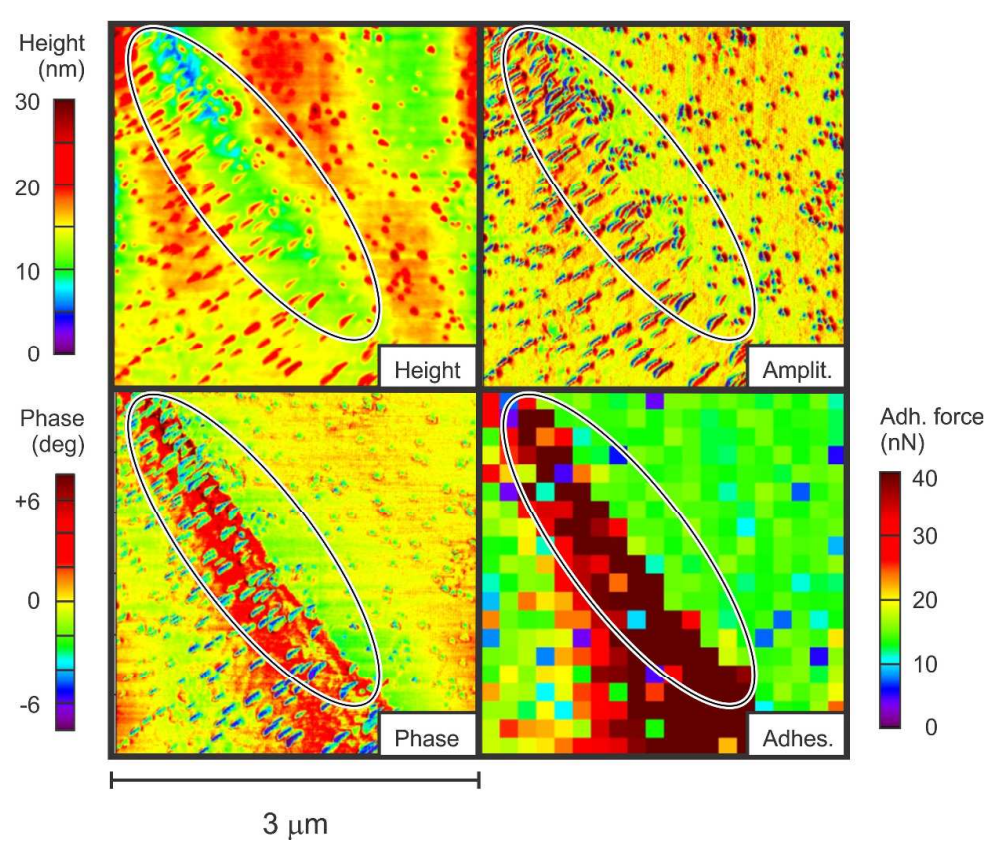

Figure 4. The AFM analysis of Lin_100 surfaces during degradation evidenced the presence of domains ranging from a few tens to about $100 \mathrm{~nm}$. These domains are absent in the same polymer before degradation and in 4 25 (either before or during degradation). The panels of the figure report maps of height (top left), amplitude (top right), phase (bottom left) and adhesion force (bottom right) for a $3 \times 3 \mu \mathrm{m}$ area. There, an area of ongoing degradation (oval) can be recognized from its lower height and higher polarity. The domains are present both in this area (possibly in higher number) and in the surrounding regions, and their lower phase values suggest to be mechanically different from the rest of the polymer. The adhesion force map does not have a sufficiently high resolution to discriminate between these domains and the rest of the polymer, but the presence of a number of isolated low-adhesion points would seem to suggest that the domains are less polar than the surrounding material. The relative elastic modulus maps are presented in Supporting Information, Figure S3. 
Therefore, it appears the polymer chains remaining in the film were only marginally affected by the hydrolytic process, whereas those on the surface seemed to undergo a degradative process similar to that of linear polymers. It thus appears logical to conclude that the hydrolysis is likely to follow a predominantly surface mechanism in the branched polymers, as opposed to the bulk one normally observed in linear PDLLA. Literature data support this interpretation; for example, Kissel et al showed that in linear and star PLGA the water uptake after 36 days incubation was respectively $21 \%$ and $2 \%{ }^{11}$. More relevant, Tsuji has recently reached essentially the same conclusion (linear- bulk / branched - surface) utilizing 4-armed star PDLLA produced through bulk polymerization $^{28}$.

\subsection{Nanoparticle preparation}

Nanoparticle preparation. Nanoparticles were produced from oil-in-water emulsions using high frequency sonication, a well-tested preparative method for polyester nanoparticles ${ }^{29}$. The choice of surfactant can heavily affect not only the colloidal stability but also the drug release kinetics and above all the cellular interactions of the nanoparticles; having above all the biological performance in mind, we have selected a PEGylated emulsifier over the more used poly(vinyl alcohol) (PVA); in particular, we have employed Pluronic L64 (PL-64), which presents a hydrophilic-lipophilic balance (HLB) value similar to that of PVA. Tween 20 and Pluronic L-35 were also trialled, but provided broader size distributions. In terms of the surfactant concentration, we have evaluated 1, 2 and 5\% wt. PL-64, with 1\% PL-64 providing significant amounts of precipitates; since 2 and 5\% offered indistinguishable results, 2\% PL-64 was chosen for all further experiments. The excess emulsifier was removed through a process of multiple pelleting and re-dispersion (see also Supporting Information, Figure S4), which did not affect the average nanoparticle size or the dispersity of their size distribution.

Since all branched polymers tested had shown a similar degradation behaviour, in this part of the study we have only used $4 \_25$ as a polymer matrix, and the Lin_100 as the linear control with 
identical molecular weight; the two polymers produced nanoparticles with similar size and size distribution (Table 2 and Figure 5A); at the end of the purification process, atorvastatin was still encapsulated with high efficiency in both polymers, and its presence (at $0.01 \% \mathrm{wt}$.) did not affect the nanoparticle size.

Finally, we have evaluated the possibility of significant nanoparticle erosion in a time frame relevant for drug release applications; we have therefore followed the size distribution for a period of 12 days (Figure 5B). The occurrence of degradative processes can be hypothesized on the basis of the increase in PDI (broader size distribution), although this did not significantly affect the average nanoparticle size. It is noteworthy that while PDLLA films underwent only a minor degradation at this time point, the vastly larger surface/volume ratio of the nanoparticles is likely to accelerate the hydrolysis kinetics.

Table 2. Physico-chemical characterization of Lin_100 and 4_25 PDLLA nanoparticles.

\begin{tabular}{|c|c|c|c|c|}
\hline System $^{\mathrm{a}}$ & $\begin{array}{c}\text { Recovery } \\
\%^{b}\end{array}$ & $\underset{\mathrm{c}}{\operatorname{Hydrodynamic} \text { size }(\mathrm{nm})}$ & $\begin{array}{l}\text { Polydispersity index } \\
\text { (PDI) }{ }^{\mathrm{c}}\end{array}$ & $\begin{array}{l}\text { Encapsulation } \\
\text { efficiency } / \%{ }^{d}\end{array}$ \\
\hline Lin_100 & 90 & $205 \pm 4$ & 0.16 & $=$ \\
\hline Lin_100 / AtSt & 73 & $200 \pm 5$ & 0.12 & $76 \pm 4.14$ \\
\hline $4 \_25$ & 80 & $175 \pm 2$ & 0.13 & $=$ \\
\hline 4_25/AtSt & 77 & $175 \pm 4$ & 0.12 & $81 \pm 4.04$ \\
\hline
\end{tabular}
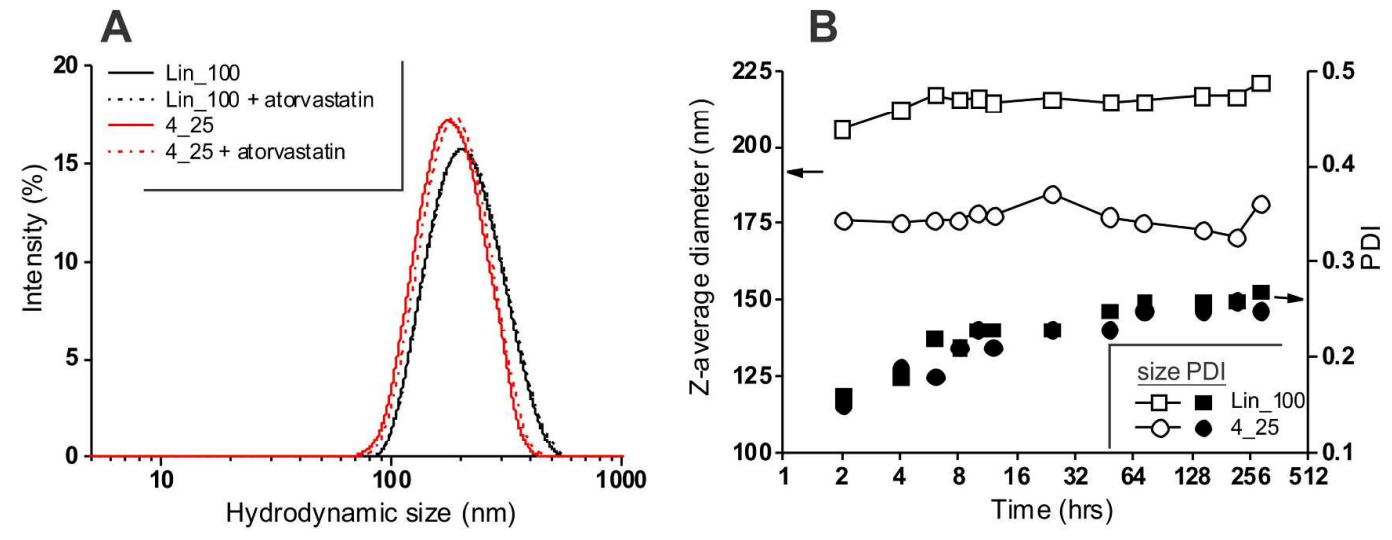
1

2

3

4

5

6

7

8

9

Figure 5. $\boldsymbol{A}$. Size distributions for the nanoparticles produced via emulsion method using $4 \_25$ as the branched polymer Lin_100 as its linear analogue. B. Nanoparticle stability in PBS at $37^{\circ} \mathrm{C}$, as determined by $\overline{\mathrm{DLS}}$. Black symbols refer to PDI values, white symbols to the Z-average size.

\subsection{Atorvastatin release from films and nanoparticles}

Theoretically, a homogeneously dispersed drug is released from a perfectly surface-degrading matrix through a zero order kinetics (constant release rate). Indeed, the release of atorvastatin from star PDLLA nanoparticles appears to follow such time dependency, whereas a first order kinetics is observed with linear polymers (Figure 5A), which would confirm the difference in the degradation mechanism. The release from polymers, however, is likely to be mechanistically more complex than a simple liberation of drug from the eroded outer layers of the matrix: for example, at day 16 about $50-60 \%$ of atorvastatin is released from films, but at that time they would have lost only about $10 \%$ of their weight. Therefore, we are inclined to consider the surface degradation of branched PDLLA as one of the factors contributing to the sustained ('zero-order-like') release of the drug, but diffusional factors may also play a significant role. However, diffusional factors are not necessarily related only to the branched PDLLA as the release of atorvastatin after 16 days from the linear samples was $\sim 75-80 \%$ after only $\sim 25 \%$ degradation with the release of atorvastatin in both linear and branched PDLLA films (Figure 6A) matching the mass loss profile in Figure 2A. This may also be reasoned as an effect of the solvent casting method resulting in a higher density of atorvastatin at the surface of the film.

The release kinetics from both Lin_100 and 4_25 nanoparticles was much accelerated in comparison to those from films (Figure 6B), as it would be expected from their much higher surface/volume ratio; additionally, the nanoparticles presented a burst phase, which corresponded to about $20 \%$ of the encapsulated drug. However, as seen for the films, branching considerably slowed down the release; the difference was particularly impressive in days $1-4$, when the drug released from the Lin_100 nanoparticles was about 70\% higher than that liberated from the 4 _25 ones. 
Additionally, at least until day 5 the branched polymer showed a zero-order-like release kinetics; this corresponded to at least $50 \%$ of atorvastatin being released at a controlled and constant rate.

In short, branching significantly slowed down the release kinetics of atorvastatin from both films and nanoparticles, making it zero-order-like; mechanistically, this is likely to be influenced by the different mechanism of degradation of the star polymers.
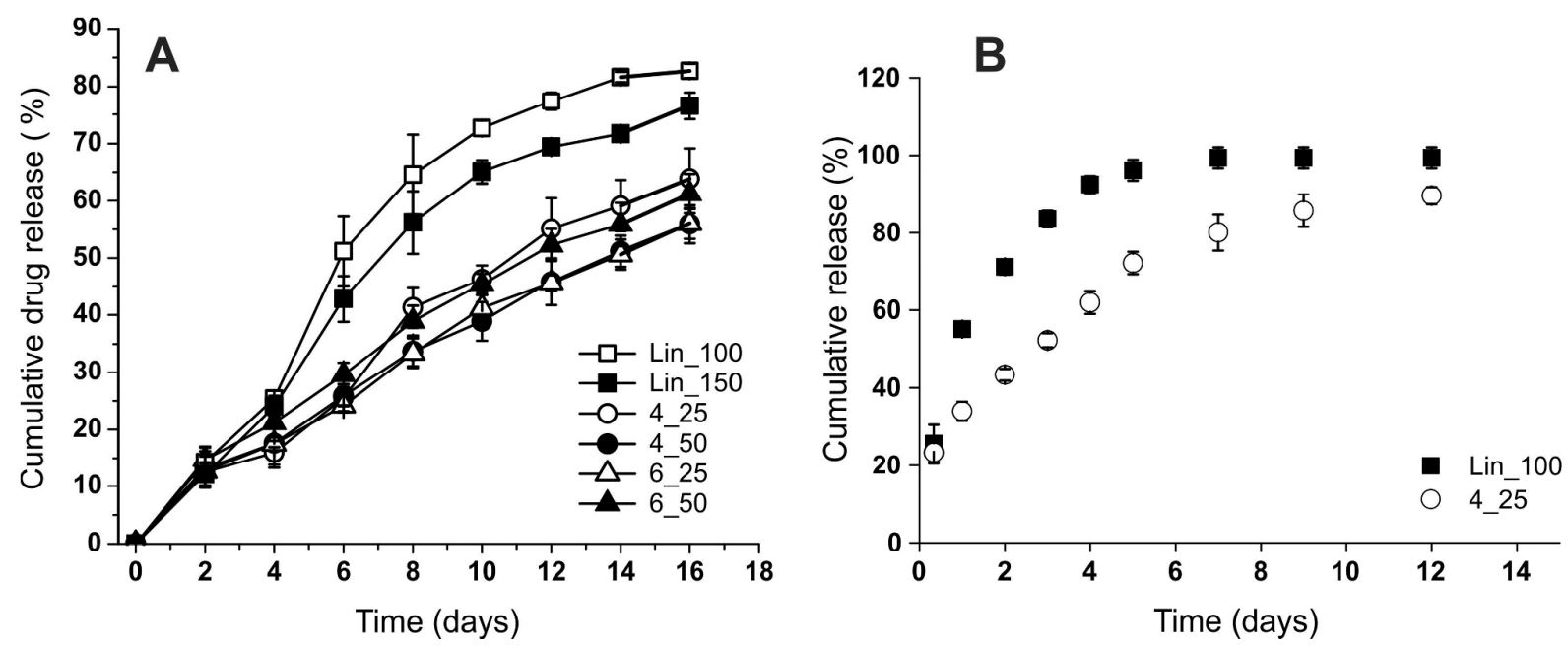

Figure 6. $\boldsymbol{A}$. Atorvastatin release at $37^{\circ} \mathrm{C}$ in water and under sink conditions from PDLLA films (thickness $\approx 370-380$ $\mu \mathrm{m}$ ) loaded with $1 \%$ wt. atorvastatin. B. at $37^{\circ} \mathrm{C}$ in water and under sink conditions from a $5 \mathrm{mg} / \mathrm{mL}$ dispersion of PDLLA nanoparticles loaded with $1 \%$ wt. atorvastatin.

\subsection{Evaluation of material toxicity}

We have employed a human osteoblastic cell line popularly used to mimic osteoblastic behaviour (NHOst) as the model target of atorvastatin, measuring their day 3 metabolic activity/viability via the Alamar blue assay; the data were normalized against the protein content of the samples, which is related to the cell number and therefore allows to provide an activity 'per cell'. By culturing the cells on PDLLA films, we predominantly assess the effect of a) cell adhesion/binding and b) any leachable material (e.g. degradation products); in experiments with nanoparticles we predominantly assess the influence of endocyted materials.

The NHOst viability was substantially identical on Lin_100 films and on reference TCPS (polystyrene) (Figure 7B); this is not surprising since it has already been shown that the adhesion 
and functionality of (murine) osteoblasts on PLLA, PGA, and their blends are comparable to those on TCPS. ${ }^{30}$ The only apparent difference is a lower cell number $(75 \%$ of the control protein content); since the cells appear indistinguishable in terms of spreading, we are inclined to ascribe to a lower proliferation rate rather than to a more difficult adhesion. When the branched 4_25 was employed as a substrate, the NHOst metabolic activity was not affected, but a significant reduction in cell numbers was observed, which was also clearly visible in microscopy images (Figure 7A). This effect may be due to a lower propensity of the branched polymer to adsorb proteins from the medium, which may be ascribed to the density of hydrophilic $\mathrm{OH}$ groups (per gram of material) which is 4-fold higher in 4_25; however, the hydrophobic terminal dodecyl chain may also participate to a higher protein adsorption on the Lin_100. Importantly, the presence of atorvastatin did not cause any significant effect either in cell metabolism or cell number.

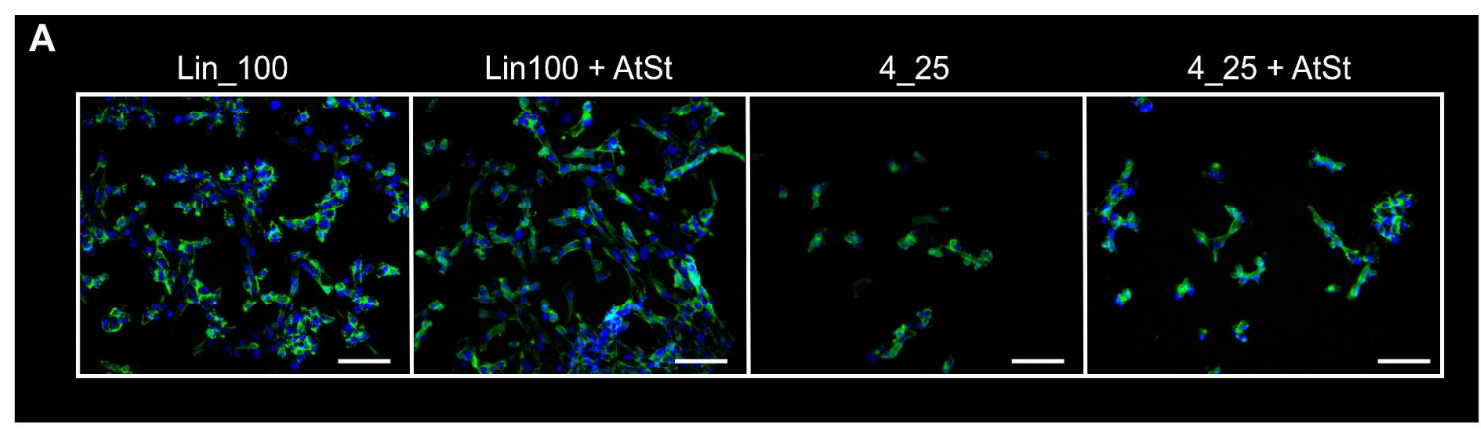

B

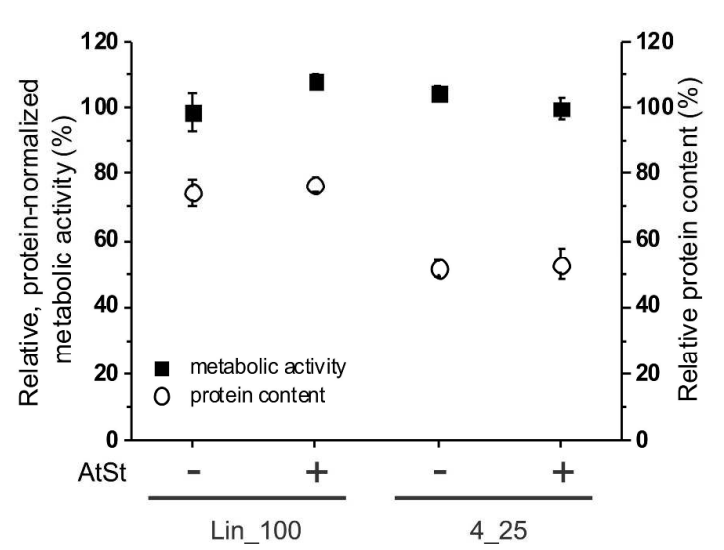

C

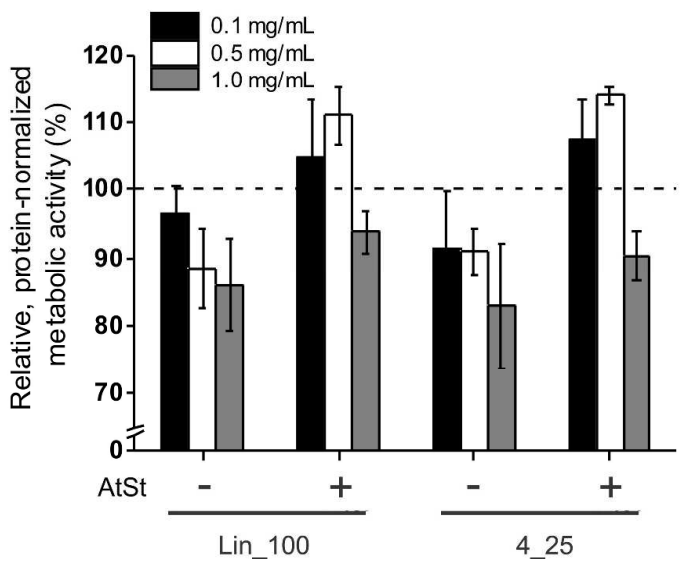

Figure 7. $\boldsymbol{A}$. Fluorescence microscopy images of NHOst cells grown on Lin_100 or $4 \_25$ films with and without $0.1 \%$ wt. atorvastatin (AtSt). Cells were stained for nucleus (blue) and phalloidin (green) after 7 days of incubation on the polymer films. Scale bars (white) $=50 \mu \mathrm{m}$. B. Day 3 metabolic activity/cell viability (Alamar blue assay results 
normalized against the protein content relative to cells grown on TCPS) and protein content (BCA assay, proportional to the cell number) of NHOst cells grown on the various PDLLA films. $C$. Day 3 metabolic activity/cell viability of NHOst cells after treatment with $0.1,0.5$ and $1 \mathrm{mg} / \mathrm{mL}$ PDLLA nanoparticles with/without $1 \%$ wt. atorvastatin. Please note that \% loading of the nanoparticles was higher than that of films to partially balance the much smaller amount of materials.

High viability was also recorded in NHOst cells exposed for 3 days to the nanoparticles (Figure 7C), independently on the linear or branched nature of PDLLA. A decrease in viability to about $85 \%$ of the control could be seen by increasing nanoparticle concentration to $1 \mathrm{mg} / \mathrm{mL}$; this was counteracted by the anabolic effects of atorvastatin (either released in a free form or liberated intracellularly after nanoparticle uptake) when the latter was loaded at $1 \%$ wt. in both kinds of nanoparticles.

It could therefore be concluded that both the presence of a branching point and that of atorvastatin produced no significant toxic effect related to either leachable or endocyted material.

\subsection{Example of functional behaviour}

The different cell adhesion on Lin_100 and 4_25 films, and the ensuing markedly different cell density did not allow a meaningful comparison of the functional behaviour of these two systems; therefore the effect of atorvastatin-releasing materials on the osteoblastic activity of NHOst cells was performed only with nanoparticles.

Statins are known to upregulate critical osteogenic markers, such as bone morphogenetic protein $2(\mathrm{BMP}-2)^{31}$, runtrelated gene $2(\mathrm{RUNX} 2)^{32}$, type I collagen (COLA1) $)^{31}$, and above all alkaline phosphatase (ALP) ${ }^{31,33}$, and this behaviour has also been observed with simvastatin released from colloidal carriers ${ }^{34}$.

Here, we have first assessed the gene expression of BMP-2, RUNX2 and COLA1 in NHOst cells exposed for three days to nanoparticles (with/without $1 \% \mathrm{wt}$. atorvastatin) and to atorvastatin in solution as a control (Figure 8A); the absence of any significant difference with the free drug confirmed the bioavailability and the osteogenic potential of atorvastatin loaded in nanoparticles (of both polymers). 

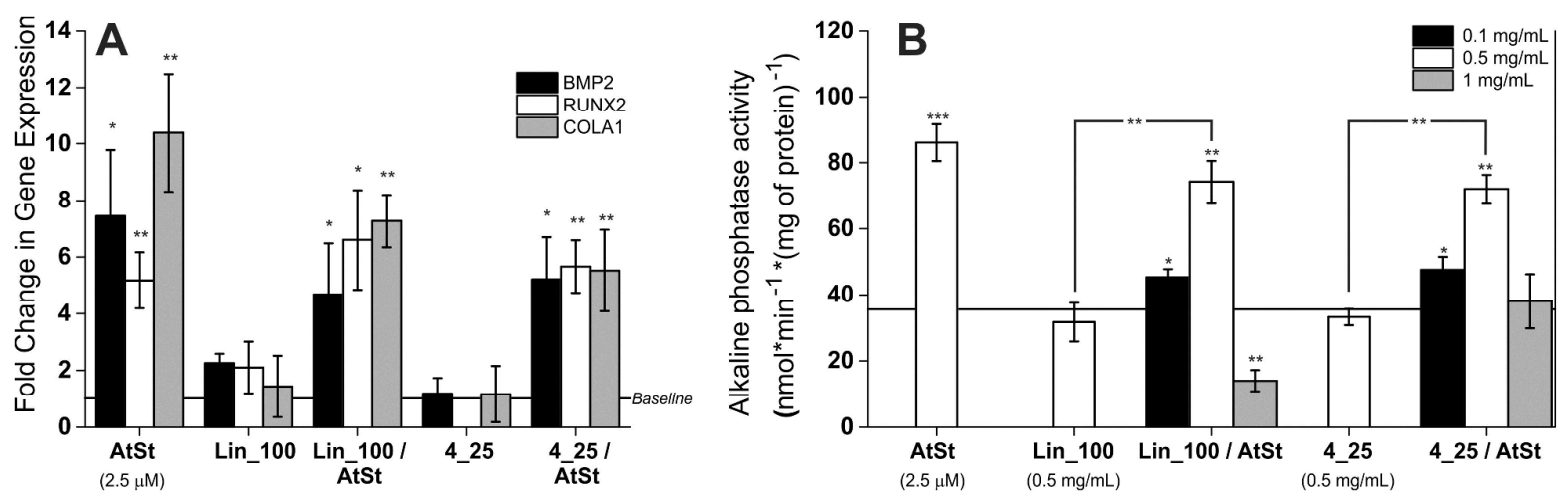

Figure 8. $\boldsymbol{A}$. Day 3 expression of BMP-2, RUNX2 and COLA1 genes (relative to untreated samples) determined via RT-PCR after exposure of NHOst cells to $0.5 \mathrm{mg} / \mathrm{mL}$ PDLLA nanoparticles (with/without $1 \%$ wt. atorvastatin) or to free atorvastatin. B. Alkaline phosphatase activity in NHOst cells measured after 3 days exposure to PDLLA nanoparticles and to free atorvastatin. The horizontal lines represent the baseline for both gene expression (panel A) and ALP activity (panel B).

We have then focused of the effects on ALP activity (Figure 8B). At a concentration of 0.5 $\mathrm{mg} / \mathrm{mL}$, the non-loaded particles induced no significant upregulation, whereas those loaded with atorvastatin increased it to levels comparable to those obtained with the free drug. It is noteworthy that in preliminary experiments with the free drug we recorded little effects for concentrations below $1 \mu \mathrm{M}$, maximum ALP activity at a $2.5 \mu \mathrm{M}$, and marked reductions at concentrations of $5 \mu \mathrm{M}$ or higher (see Supporting Information, Figure S5). A similarly narrow therapeutic window is possibly offered also by the nanoparticles: at $0.1 \mathrm{mg} / \mathrm{mL}$ the increase in ALP activity was significant but modest, at $0.5 \mathrm{mg} / \mathrm{mL}$ we observed a large increase, whereas at $1.0 \mathrm{mg} / \mathrm{mL}$ the activity dropped. In particular, with $4 \_25$ nanoparticles the activity decreased to levels similar to the untreated samples, with for Lin_100 ones to much lower levels, mirroring the lower cell viability observed at that concentration (Figure 7C). We interpret this difference between linear and star polymers to the more rapid release of the drug from the Lin_100 nanoparticles (Figure 6A), likely leading to a higher atorvastatin concentration and therefore to a steeper drop in ALP activity at 1 $\mathrm{mg} / \mathrm{ml}$ (Figure 8B). The slower release kinetics (and reduced burst release) in the branched PDLLA nanoparticles can therefore be beneficial to reduce the likelihood of drug overdosing. 


\section{Conclusion}

The introduction of branching appears to significantly affect both the degradation behaviour of PDLLA and the kinetics of drug release from it, both for polymer films and nanoparticles. Our results on films suggest that a) star polymers probably degrade via a surface mechanism, with a slower kinetics than the bulk-degrading linear ones, b) neither the functionality of the single branching point (4- or 6-armed stars) nor the degree of polymerization of the arms (25 or 50 units per arm) appeared to significantly affect these properties. It is noteworthy that the slower degradation of branched PDLLA seems to contrast with some earlier reports on other polyesters; for example, PEG-block-oligoesters ${ }^{12}$ have been reported to degrade faster (see introduction), but this may be due to the peculiarity of the PEGylated polymers, which are considerably more hydrophilic than the PDLLA studied here.

In a preliminary evaluation of these materials as potential drug releasing vehicles, the poor adhesion of cells on films of star PDLLA hampered their direct use as cell culture substrates; the nanoparticles, on the other hand, showed that linear and branched polymers allowed both for high loading efficiency and bioavailability of a model drug, i.e. atorvastatin; the slower release kinetics of the drug from 4_25 was likely responsible for the different concentration dependency of ALP activity in the linear vs. branched polymer nanoparticles.

\section{Associated Content}

The following files are available free of charge.

Molecular weight distributions obtained via GPC, film thicknesses, relative elastic modulus maps acquired via AFM, a scheme of the process of nanoparticle purification, alkaline phosphatase activity can be found in the Supporting Information. 
Author Information

\section{Corresponding Author}

*E-mail: nicola.tirelli@manchester.ac.uk

*E-mail: sarah.cartmell@manchester.ac.uk

Notes

The authors declare no competing financial interest.

\section{Acknowledgements}

JB is indebted with BBSRC for a DTP studentship, RDo with AstraZeneca for co-funding NoWCADD. The authors want to thank Dr. Enrique Lallana (NoWCADD) for the useful discussions and the help in NMR measurements. AFM images were acquired at the BioAFM Facility of the University of Manchester.

\section{References}

1. d'Arcy, R.; Burke, J.; Tirelli, N., Branched polyesters: Preparative strategies and applications. $A d v$. Drug. Delivery Rev. 2016 doi: 10.1016/j.addr.2016.05.005.

2. Li, X. J.; Qian, Y. F.; Liu, T.; Hu, X. L.; Zhang, G. Y.; You, Y. Z.; Liu, S. Y., Amphiphilic multiarm star block copolymer-based multifunctional unimolecular micelles for cancer targeted drug delivery and MR imaging. Biomaterials 2011, 32, (27), 6595-6605.

3. Yang, X. Q.; Grailer, J. J.; Pilla, S.; Steeber, D. A.; Gong, S. Q., Tumor-Targeting, pH-Responsive, and Stable Unimolecular Micelles as Drug Nanocarriers for Targeted Cancer Therapy. Bioconjugate Chem. 2010, 21, (3), 496-504.

4. Cameron, D. J. A.; Shaver, M. P., Aliphatic polyester polymer stars: synthesis, properties and applications in biomedicine and nanotechnology. Chem. Soc. Rev. 2011, 40, (3), 1761-1776.

5. Wang, L.; Cai, C.; Dong, C.-M., Synthesis, Characterisation and Nanoparticle Formation of StarShaped Poly(L-Lactide) With Six Arms. Chin. J. Polym. Sci. 2008, 26, (02), 161-169.

6. Zhao, Y.; Li, J.; Yu, H.; Wang, G.; Liu, W., Synthesis and characterization of a novel polydepsipeptide contained tri-block copolymer (mPEG-PLLA-PMMD) as self-assembly micelle delivery system for paclitaxel. Int. J. Pharm. 2012, 430, (1-2), 282-91. 
7. Kontoyianni, C.; Sideratou, Z.; Theodossiou, T.; Tziveleka, L. A.; Tsiourvas, D.; Paleos, C. M., A novel micellar PEGylated hyperbranched polyester as a prospective drug delivery system for paclitaxel. Macromol. Biosci. 2008, 8, (9), 871-81.

8. Biela, T.; Duda, A.; Rode, K.; Pasch, H., Characterization of star-shaped poly(l-lactide)s by liquid chromatography at critical conditions. Polymer 2003, 44, (6), 1851-1860.

9. Kang, N.; Leroux, J.-C., Triblock and star-block copolymers of N-(2-hydroxypropyl)methacrylamide or N-vinyl-2-pyrrolidone and d,l-lactide: synthesis and self-assembling properties in water. Polymer 2004, 45, (26), 8967-8980.

10. Kricheldorf, H. R.; Ahrensdorf, K.; Rost, S., Polylactones, 68. Macromol. Chem. Phys. 2004, 205, (12), 1602-1610.

11. Kissel, T.; Brich, Z.; Bantle, S.; Lancranjan, I.; Nimmerfall, F.; Vit, P., Parenteral depot-systems on the basis of biodegradable polyesters. J. Control. Release 1991, 16, (1), 27-41.

12. Breitenbach, A.; Li, Y. X.; Kissel, T., Branched biodegradable polyesters for parenteral drug delivery systems. J. Control. Release 2000, 64, (1-3), 167-78.

13. Breitenbach, A.; Pistel, K. F.; Kissel, T., Biodegradable comb polyesters. Part II. Erosion and release properties of poly(vinyl alcohol)-g-poly(lactic-co-glycolic acid). Polymer 2000, 41, (13), 4781-4792.

14. Ghassemi, A. H.; van Steenbergen, M. J.; Barendregt, A.; Talsma, H.; Kok, R. J.; van Nostrum, C. F.; Crommelin, D. J. A.; Hennink, W. E., Controlled Release of Octreotide and Assessment of Peptide Acylation from Poly(D,L-lactide-co-hydroxymethyl glycolide) Compared to PLGA Microspheres. Pharm. Res. 2012, 29, (1), 110-120.

15. McKay, A.; Leung, B. P.; McInnes, I. B.; Thomson, N. C.; Liew, F. Y., A novel anti-inflammatory role of simvastatin in a murine model of allergic asthma. J. Immunol. 2004, 172, (5), 2903-2908.

16. Paumelle, R.; Blanquart, C.; Briand, O.; Barbier, O.; Duhem, C.; Woerly, G.; Percevault, F.; Fruchart, J. C.; Dombrowicz, D.; Glineur, C.; Staels, B., Acute antiinflammatory properties of statins involve peroxisome proliferator-activated receptor-alpha via inhibition of the protein kinase $\mathrm{C}$ signaling pathway. Circ. Res. 2006, 98, (3), 361-369.

17. Mundy, G.; Garrett, R.; Harris, S.; Chan, J.; Chen, D.; Rossini, G.; Boyce, B.; Zhao, M.; Gutierrez, G., Stimulation of bone formation in vitro and in rodents by statins. Science 1999, 286, (5446), 1946-1949.

18. Oryan, A.; Kamali, A.; Moshiri, A., Potential mechanisms and applications of statins on osteogenesis: Current modalities, conflicts and future directions. J. Control. Release 2015, 215, 12-24.

19. Jadhav, S. B.; Jain, G. K., Statins and osteoporosis: new role for old drugs. J. Pharm. Pharmacol. 2006, 58, (1), 3-18.

20. Piskin, E.; Isoglu, I. A.; Bolgen, N.; Vargel, I.; Griffiths, S.; Cavusoglu, T.; Korkusuz, P.; Guzel, E.; Cartmell, S., In vivo performance of simvastatin-loaded electrospun spiral-wound polycaprolactone scaffolds in reconstruction of cranial bone defects in the rat model. J. Biomed. Mater. Res. Part A 2009, 90A, (4), 1137-1151.

21. Stein, E. A.; Lane, M.; Laskarzewski, P., Comparison of statins in hypertriglyceridemia. Am. J. Cardiol. 1998, 81, (4A), 66B-69B.

22. Korhonen, H.; Helminen, A.; Seppälä, J. V., Synthesis of polylactides in the presence of co-initiators with different numbers of hydroxyl groups. Polymer 2001, 42, (18), 7541-7549.

23. Kim, S. H.; Han, Y.-K.; Kim, Y. H.; Hong, S. I., Multifunctional initiation of lactide polymerization by stannous octoate/pentaerythritol. Makromol. Chem. 1992, 193, (7), 1623-1631. 
1

2

3

4

5

6

7

8

9

24. Dong, C. M.; Qiu, K. Y.; Cu, Z. W.; Feng, X. D., Synthesis of star-shapee poly(epsiloncaprolactone)-b-poly(DL-lactic acid-alt-glycolic acid) with multifunctional initiator and stannous octoate catalyst. Macromolecules 2001, 34, (14), 4691-4696.

25. Braun, B.; Dorgan, J. R.; Dec, S. F., Infrared spectroscopic determination of lactide concentration in polylactide: An improved methodology. Macromolecules 2006, 39, (26), 9302-9310.

26. Kim, S. H.; Han, Y.-K.; Ahn, K.-D.; Kim, Y. H.; Chang, T., Preparation of star-shaped polylactide with pentaerythritol and stannous octoate Makromol. Chem. 1993, 194, 3229-3236.

27. Kim, E. S.; Kim, B. C.; Kim, S. H., Structural Effect of Linear and Star-Shaped Poly(L-lactic acid) on Physical Properties. J. Polym. Sci. Pol. Phys. 2004, 42, 939 -946.

28. Tsuji, H.; Hayashi, T., Hydrolytic degradation of linear 2-arm and branched 4-arm poly(DLlactide)s: Effects of branching and terminal hydroxyl groups. Polym. Degrad. Stabil. 2014, 102, 59-66.

29. Keum, C. G.; Noh, Y. W.; Baek, J. S.; Lim, J. H.; Hwang, C. J.; Na, Y. G.; Shin, S. C.; Cho, C. W., Practical preparation procedures for docetaxel-loaded nanoparticles using polylactic acid-co-glycolic acid. Int. J. Nanomed. 2011, 6, 2225-2234.

30. Ishaug, S. L.; Yaszemski, M. J.; Bizios, R.; Mikos, A. G., Osteoblast function on synthetic biodegradable polymers. J. Biomed. Mater. Res. 1994, 28, (12), 1445-53.

31. Maeda, T.; Matsunuma, A.; Kurahashi, I.; Yanagawa, T.; Yoshida, H.; Horiuchi, N., Induction of osteoblast differentiation indices by statins in MC3T3-E1 cells. J. Cell. Biochem. 2004, 92, (3), 458-471.

32. Qiao, L. J.; Kang, K. L.; Heo, J. S., Simvastatin promotes osteogenic differentiation of mouse embryonic stem cells via canonical Wnt/beta-catenin signaling. Mol. Cells 2011, 32, (5), 437-444.

33. Song, C. L.; Guo, Z. Q.; Ma, Q. J.; Chen, Z. Q.; Liu, Z. J.; Jia, H. T.; Dang, G. T., Simvastatin induces osteoblastic differentiation and inhibits adipocytic differentiation in mouse bone marrow stromal cells. Biochem. Biophys. Res. Commun. 2003, 308, (3), 458-462.

34. Liu, X. N.; Li, X. R.; Zhou, L.; Li, S. B.; Sun, J.; Wang, Z. L.; Gao, Y.; Jiang, Y.; Lu, H. B.; Wang, Q. B.; Dai, J. W., Effects of simvastatin-loaded polymeric micelles on human osteoblast-like MG-63 cells. Colloid Surf. B-Biointerfaces 2013, 102, 420-427. 
Table of Contents graphic

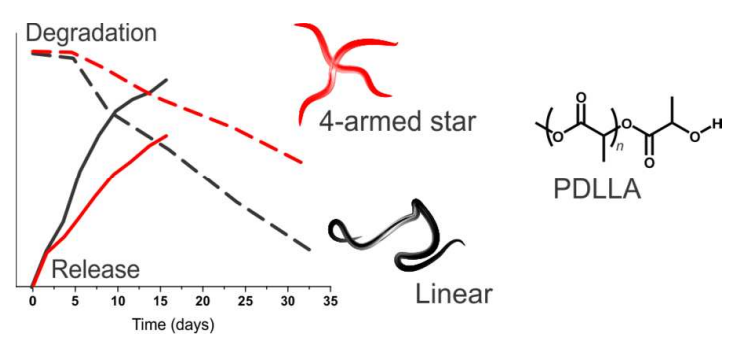

14

15

16

17

18

19

20

21

22

23

24

25

26

27

28

29

30

31

32

33

34

35

36

37

38

39

40

41

42

43

44

45

46

47

48

49

50

51

52

53

54

55

56

57

58

59

60 
1
2
3
4
5
6
7
8
9
10
11
12
13
14
15
16
17
18
19
20
21
22
23
24
25
26
27
28
29
30
31
32
33
34
35
36
37
38
39
40
41
42
43
44
45
46
47
48
49
50
51
52
53
54
55
56
57
59
60 


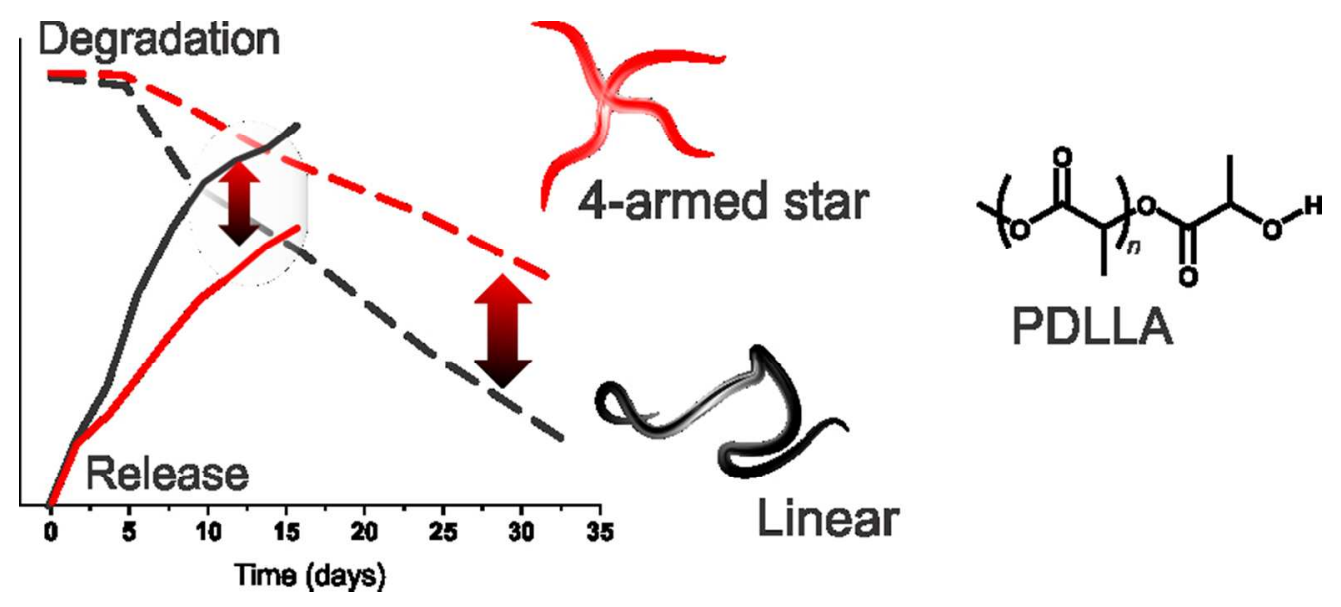

\author{
ToC graphic \\ $76 \times 33 \mathrm{~mm}(300 \times 300$ DPI $)$
}

